\title{
De l'idéal démocratique de l'équilibre à la réalité politique du déséquilibre des pouvoirs
}

From the democratic ideal of balance to the political reality of power imbalance

\section{Éric Fokou}

\section{(2) OpenEdition}

\section{Journals}

Édition électronique

URL : https://journals.openedition.org/add/1807

DOI : 10.4000/add. 1807

ISSN : 2606-1988

Éditeur

Presses universitaires de Rouen et du Havre

\section{Édition imprimée}

Date de publication : 1 juin 2020

Pagination : 37-68

ISBN : 979-10-240-1442-5

ISSN : 1955-0855

Référence électronique

Éric Fokou, "De l'idéal démocratique de l'équilibre à la réalité politique du déséquilibre des pouvoirs », Les Annales de droit [En ligne], 14 | 2020, mis en ligne le 01 juin 2021, consulté le 12 janvier 2023. URL : http://journals.openedition.org/add/1807 ; DOI : https://doi.org/10.4000/add.1807

Ce document a été généré automatiquement le 12 janvier 2023.

Tous droits réservés 


\section{De l'idéal démocratique de l'équilibre à la réalité politique du déséquilibre des pouvoirs}

From the democratic ideal of balance to the political reality of power imbalance

\section{Éric Fokou}

1 «C'est pour lire Locke, et non Shakespeare, que les Français vont s'appliquer à apprendre l'anglais ${ }^{1}$.» Fort révélatrice, cette observation de Bastide témoigne, à suffisance, de l'emprise de la pensée lockéenne dans la philosophie politique francophone et contemporaine par extrapolation ${ }^{2}$. L'influence de la pensée politique libérale de l'auteur du célèbre Traité du gouvernement civil $^{3}$ et grand inspirateur de la Déclaration des droits de l'homme et du citoyen de 1789 (DDHC), fut encore plus importante puisque c'est à lui que revient l'honneur d'avoir pensé, quoique de façon inachevée, les prémisses d'une théorie de la séparation des pouvoirs dont le corollaire nécessaire demeure l'équilibre des pouvoirs avec lequel elle se confond foncièrement. Cette brève précision sur l'histoire des idées politiques occidentales s'impose de prime abord, d'autant plus que la paternité de la séparation des pouvoirs est souvent faussement et/ ou idéologiquement attribuée dans la littérature française et francophone au baron de La Brède et de Montesquieu, Charles-Louis de Secondat, qui n'eut pourtant que le mérite d'en proposer une véritable systématisation. En réalité, les premières origines d'une théorie de la séparation ou plus exactement de l'équilibre des pouvoirs remonteraient chez les philosophes grecs post-socratiques, en particulier, Platon dans La République ${ }^{4}$ et Les Lois ${ }^{5}$, Aristote dans La Politique ${ }^{6}$. Après Locke et Montesquieu, elle sera reprise et poursuivie par nombre de penseurs libéraux comme Jean-Jacques Rousseau, Emmanuel-Joseph Sieyès, Alexis de Tocqueville, Charles Eisenmann, Louis Althusser, Raymond Carré de Malberg, etc. Tous considèrent que la séparation des pouvoirs serait une condition sine qua non de leur équilibre.

2 Toute personne ou organe détenteur d'un pouvoir aurait tendance à en abuser, nous le rappelait, non sans raison, Montesquieu. Ce constat atemporel, valable pour l'homme, l'est tout autant pour les institutions qu'il crée, contrôle et incarne. L'homme n'est-il 
pas d'ailleurs une composante essentielle des institutions sociales? Bien avant Montesquieu, John Locke l'avait très tôt compris en préconisant dans sa sociologie des institutions une séparation des pouvoirs législatif, exécutif et confédératif au sein de l'État afin d'en limiter l'abus'. Cette séparation constituerait une forme d'autolimitation $\mathrm{du}$ pouvoir, voire le seul moyen d'inter-neutralisation des pouvoirs exécutif, judiciaire et législatif dans la théorie moderne de l'État et de la séparation des pouvoirs. L'on présuppose que la limitation du pouvoir ne pourrait se faire efficacement que par l'instauration d'un équilibre entre les différents pouvoirs constitutifs de l'État. L'équilibre des pouvoirs serait ainsi le gage même d'un type idéal de démocratie ${ }^{8}$, "gouvernement du peuple par le peuple pour le peuple" selon l'heureuse formule d'Abraham Lincoln par ailleurs consacrée par l'article 2 de la Constitution de la $\mathrm{V}^{e}$ République française. Il est garant des droits et libertés des citoyens contre l'arbitraire des institutions et des gouvernants toujours tentés par la centralisation et la concentration des pouvoirs. De ce long processus d'idéation et d'institutionnalisation initié dès la modernité politique et accentué depuis l'avènement de l'État-nation, que reste-t-il de l'équilibre des pouvoirs dans les démocraties (néo)libérales postmodernes et/ou dans ce qui peut être considéré comme leurs avatars plus ou moins pervertis dans les sociétés postcoloniales notamment d'outre-Atlantique et d'Afrique continentale? En d'autres termes, peut-on défendre ou pourfendre aujourd'hui l'idée que l'équilibre des pouvoirs est une réalité empirique dans un contexte de démocratie libérale ${ }^{9}$ ? Il s'agit là d'un questionnement métajuridique qui déborde le seul cadre de la théorie du droit et aborde sans tabou le droit comparé, la philosophie politique, la sociologie des institutions et les considérations méthodologiques sur l'évolution des systèmes constitutionnels contemporains. Pour y répondre, il convient de partir de la construction métempirique (c'est-à-dire qui dépasse l'expérience et n'est pas fondée sur la connaissance positive) de l'idéalité de l'équilibre des pouvoirs en tant que dogme fondateur de la démocratie libérale et de la légitimité de l'ordre étatique (1) vers la réalité politique du déséquilibre contextuel et inconstant des pouvoirs dans tous les régimes politiques postmodernes (2).

\section{L'équilibre des pouvoirs : un idéaltype en démocratie libérale}

3 La théorie ou encore le principe de l'équilibre des pouvoirs demeure par-dessus tout un idéaltype (idealtypus) au sens wébérien du terme, c'est-à-dire une utopie réflexive ${ }^{10}$. D'un point de vue juridique, il trouve son fondement dans le grand principe, voire la théorie constitutionnelle de la séparation des pouvoirs ${ }^{11}$. Ces deux principes ou théories complémentaires ont une portée dogmatique et ne sont en réalité que des mécanismes de limitation et de légitimation du pouvoir (1.1) qui permettent supposément de garantir les droits et libertés des citoyens dans le mythe de l'État de droit ${ }^{12}$ s'affirmant aux antipodes de l'arbitraire des institutions et des gouvernants ${ }^{13}(1.2)$.

\subsection{Un mécanisme de limitation et de légitimation du pouvoir}

4 L'équilibre des pouvoirs est un principe consubstantiel à celui de la séparation constitutionnelle des pouvoirs. Dans la théorie politique et constitutionnelle, la séparation des pouvoirs désigne traditionnellement l'indépendance des trois fonctions 
essentielles ou pouvoirs constitutifs de l'État: législatif, exécutif et judiciaire. Cette indépendance fonctionnelle offre une garantie de l'équilibre entre les trois pouvoirs qui se contrôlent, pour ainsi dire, mutuellement. Chaque pouvoir agirait comme un contrepouvoir pour les autres (checks and balances). Ils font partie intégrante des principes élémentaires de la démocratie libérale dont ils constituent le socle. L'on parle à bon droit de "double principe constitutionnel de la séparation et de l'équilibre des pouvoirs ${ }^{14}$ » en tant qu'élément essentiel de la démocrati ${ }^{15}$. Dans le contexte d'une démocratie libérale de type occidental qui renvoie in globo à une forme de gouvernement présidentiel ou parlementaire (primo-ministériel) garantissant des droits et libertés à tous les citoyens, la séparation des pouvoirs suppose donc que les fonctions législative, exécutive et judiciaire soient indépendantes au sein d'un État dit de droit (par opposition à l'État de non-droit ou de dictature). Elle assure par ricochet la souveraineté du peuple à travers ses représentants élus, l'indépendance de la justice rendue en son nom tout en évitant le "gouvernement des juges", la dictature du parlement et l'absolutisme du gouvernement. Elle s'affirme alors aux antipodes d'une concentration ou confusion des pouvoirs de l'État aux mains d'un individu ou encore d'une seule institution, caractéristique des régimes autocratiques, despotiques et dictatoriaux. L'équilibre des pouvoirs est présumé être garanti par un système de contrôle mutuel des poids et contrepoids institué par les dispositions de la constitution. La faculté pour le chef de l'État ou de l'exécutif de dissoudre l'une des chambres du Parlement et de convoquer des élections anticipées, la possibilité pour le pouvoir législatif de renverser le gouvernement et la soumission des magistrats du parquet à l'autorité hiérarchique du gouvernement sont souvent présentées comme autant d'illustrations révélatrices de cet équilibre des pouvoirs en contexte de démocratie libérale. Mais comme l'a si bien noté un philosophe du droit : « depuis trois siècles, la séparation des pouvoirs joue un rôle important dans notre imaginaire politique et juridique. À vrai dire, personne ne s'est jamais fait trop d'illusions sur sa réalité : il s'agit bien d'une doctrine, non d'un fait ou d'une théorie scientifique ${ }^{16}$. » Vraie pour la séparation des pouvoirs, qualifiée à juste titre de «formidable "casse-tête" intellectuel posé aux analystes de la chose constitutionnelle ${ }^{17}$ ", cette observation l'est tout autant pour son corollaire l'équilibre des pouvoirs. Une étude de cas sur la République française permet en effet de constater que l'équilibre des pouvoirs n'est ni plus ni moins qu'une utopie constitutionnelle ${ }^{18}$.

5 L'idéal de la séparation et de l'équilibre des pouvoirs est en principe consacré par la constitution et garanti en pratique par la juridiction constitutionnelle. Le pouvoir législatif incarné par le Parlement, considéré comme le premier pouvoir du fait de sa légitimité démocratique en tant que représentant $d u$ peuple, exerce la fonction suprême d'adoption des lois, le pouvoir exécutif incarné par le gouvernement exerce la fonction secondaire d'exécution des lois tandis que le pouvoir judiciaire s'occupe de la fonction subsidiaire de rendre la justice conformément à la loi, au nom du peuple. Il faut d'ailleurs dénoter que le pouvoir judiciaire, souvent renié par ses contempteurs ${ }^{19}$, était originairement et historiquement rattaché à la fonction exécutive dont il ne serait qu'une déclinaison ou dimension complémentaire jusqu'à la nécessité impérieuse de garantir l'indépendance de la justice, cette dernière étant le véritable levier et garant de l'équilibre en cas d'empiétement ou de conflits de compétence entre les différents pouvoirs. Dans le constitutionnalisme contemporain, la séparation des pouvoirs peut revêtir deux formes : une séparation étanche des pouvoirs (séparation-répartition des pouvoirs) et une séparation perméable des pouvoirs (séparation-collaboration des 
pouvoirs). Selon la doctrine classique, la séparation dite étanche qui suppose une répartition stricte des fonctions ou compétences entre les différents pouvoirs serait celle qui garantirait le mieux l'équilibre, mais s'avérerait chimérique et inefficace en matière de gouvernance publique, contrairement à la séparation perméable qui assure une meilleure unité fonctionnelle et organique de l'État ainsi que l'efficacité de l'action publique. La séparation étanche des pouvoirs pourrait même aboutir dans le pire des cas à une paralysie des institutions comme ce fut le cas dans l'histoire de la France sous le Directoire (1795-1799) et la II République (1848-1851) avec en prime des coups d'État à chaque fois. Ainsi, les différents pouvoirs, au nom du principe de l'unité de l'État, ne peuvent fonctionner en vase clos et se doivent de collaborer dans l'intérêt du service public ou de la puissance publique. La séparation fonctionnelle des pouvoirs doit donc pouvoir se concilier avec l'unité organique de l'État.

L'idéal de la séparation et de l'équilibre des pouvoirs - en ce qu'il fonde l'imaginaire social de la démocratie libérale et participe à son jeu dans des règles de droit supposées préétablies au nom du peuple et pour le peuple - constitue surtout un instrument efficace de légitimation du pouvoir des institutions et des gouvernants qui l'exercent vis-à-vis des gouvernés. Ceux-ci auront le sentiment de vivre en toute sécurité juridique dans une société où les règles doivent être respectées par tous, y compris les institutions et les détenteurs du pouvoir qui les ont faites (patere legem quam ipse fecisti). Car nul n'est, officiellement, au-dessus de la loi qui s'impose à tous en toute égalité. Une épistémologie des théories juridiques notamment quant à leur valeur de vérité du doyen Georges Vedel ${ }^{20}$, dont s'inspire Michel Troper dans sa théorie (néo)réaliste du droit, permet de mieux comprendre cet état de choses et du droit. En effet, pour Vedel comme pour Troper, "une théorie [même fausse] peut être dite "vraie" si elle est indispensable pour fonder une pratique juridique ${ }^{21} »$. Par transposition au cas d'espèce, la théorie de la séparation et de l'équilibre des pouvoirs serait « vraie » seulement pour une raison essentielle en droit: elle permet de fonder la pratique institutionnelle de l'État et lui confère plus de crédibilité, de légitimité et d'acceptabilité aux yeux de la communauté sociale. Elle assure symboliquement une meilleure fonction sociale du pouvoir ou des pouvoirs de l'État ainsi qu'une meilleure division du travail en son sein. En consacrant une telle théorie dans le discours officiel du droit, le peuple, sans craindre l'arbitraire des différents pouvoirs de l'État, accepte de lui prêter allégeance et de faire confiance aux institutions. Le dogme de la séparation et de l'équilibre des pouvoirs en tant qu'instrument de légitimation du pouvoir et de soumission des gouvernés aux institutions et donc aux gouvernants qui les incarnent en pratique est d'autant plus légitime aux yeux des citoyens qu'il est présenté comme la seule garantie efficace de leurs droits et libertés contre l'arbitraire de ces institutions.

\subsection{Une garantie de l'État de droit contre l'arbitraire du pouvoir}

7 L'idéal de la séparation et de l'équilibre des pouvoirs est considéré comme un pilier de la démocratie libérale en ce qu'il assure a priori un contrôle du pouvoir par le pouvoir. Cet intercontrôle des différents pouvoirs législatif, exécutif et judiciaire se met en branle notamment dans le cadre du respect du droit positif auquel sont soumis tous les trois pouvoirs et au sein duquel trône la constitution en tant que norme fondamentale de l'État (post) moderne. À ce titre, au sens, par exemple, des dispositions de l'article 16 de la DDHC, «toute société dans laquelle la garantie des droits n'est pas assurée ni la séparation des pouvoirs déterminée, n’a point de Constitution ». Autrement dit, toute 
constitution pour être « juridiquement » ou démocratiquement valide doit garantir une séparation des pouvoirs au sein de l'État. La séparation et l'équilibre des pouvoirs sont ainsi érigés en garantie constitutionnelle et institutionnelle des droits fondamentaux du citoyen contre l'arbitraire et l'absolutisme du pouvoir de l'État et au sein de l'État. Ils trouvent tout leur sens et fondement dans cette formule sentencieuse de Montesquieu :

c'est une expérience éternelle que tout homme qui a du pouvoir est porté à en abuser; il va jusqu'à ce qu'il trouve des limites [...] La vertu même a besoin de limite. Pour qu'on ne puisse abuser du pouvoir, il faut que, par la disposition des choses, le pouvoir arrête le pouvoir ${ }^{22}$.

Il n'y a point encore de liberté si la puissance de juger n'est pas séparée de la puissance législative et de l'exécutrice. Si elle était jointe à la puissance législative, le pouvoir sur la vie et la liberté des citoyens serait arbitraire : car le juge serait législateur. Si elle était jointe à la puissance exécutrice, le juge pourrait avoir la force d'un oppresseur ${ }^{23}$

8 L'idéal de la séparation et de l'équilibre des pouvoirs s'en trouve érigé en idéal démocratique et en sacro-saint principe de justice et de bonne gouvernance des institutions ${ }^{24}$. Il est censé, par cette symbolique, garantir au mieux l'État de droit contre l'injustice des dépositaires du pouvoir à l'encontre des citoyens toujours épris de droits et libertés ${ }^{25}$. Ces droits et libertés sont «religieusement considérés par les citoyens croyants qui y croient " comme des pouvoirs d'origine divine, naturelle ou légale « reconnus à l'individu, garantis par un contrôle juridictionnel, et qui reposent sur cette croyance politique d'être, dans leur principe, supérieurs aux gouvernants chargés seulement de les organiser en vue des nécessités de la vie en commun ${ }^{26} »$.

La garantie institutionnelle de ces droits et libertés est consolidée par une indépendance du pouvoir judiciaire qui veille, pour ainsi dire, en dernier ressort au respect de l'État de droit. Un État de droit où « aucun droit n'existe en dehors de l'État, et [où] il n'existe pas d'État en dehors du droit [où] aucun juste non plus ne peut exister, s'il ne reconnaît l'État comme l'instance la plus proche de l'Idée ${ }^{27}$ ", de la vérité et de la justice. Un État de droit qui définit par sa loi des droits, voire les croyances "religieusement» légales auxquelles doivent croire les heureux citoyens. Cette propagande de légitimation et de soumission des citoyens sujets de droit à l'État suzerain auquel ils doivent foi et salut, relève, somme toute, de l'ordre d'un étatisme romantique ou d'un romantisme théologico-politique comme l'a si bien démontré l'ordo-libéraliste Carl Schmitt ${ }^{28}$. Un romantisme illusoire trop beau pour être tout bonnement vrai, comme le confesse l'anarcho-libertariste Bakounine pour qui la liberté, droit suprême de l'individu de même que son expression authentique par le peuple, ne peut trouver son essence, son ressort et son essor qu'en dehors de l'État, fûtil de droit, démocratique ou théocratique ${ }^{29}$. Car, l'État de droit serait, en définitive, « un dieu qui promet aux hommes tranquillité, sécurité et ordre pour leur "existence physique ici-bas", mais qui ne sait pas atteindre leurs âmes et qui laisse insatisfaite leur aspiration la plus profonde ${ }^{30}$ ». L'État même de droit est de ce point de vue plus une négation, une déception et moins qu'une expression des droits et libertés des citoyens assujettis à son ordre juridico-théologico-politique.

L'idéal de l'équilibre des pouvoirs qui n'est à maints égards qu'une fiction juridique et constitutionnelle légitimant l'ordre théologico-politique établi par l'État suzerain à travers ses entités souveraines prévalant dans une démocratie parfaite, à nulle autre pareille dans le monde des hommes, ne doit cependant pas occulter la réalité politique 
et empirique du déséquilibre inconstant des pouvoirs observable dans tout régime politique, soient-ils démocratiques ou autocratiques.

\section{Le déséquilibre contextuel des pouvoirs : une réalité politique}

11 Considérer qu'il y a un équilibre des pouvoirs en contexte de démocratie libérale revient à méconnaître le jeu et les enjeux du déséquilibre des pouvoirs dans les régimes politiques modernes et postmodernes. Considérer l'équilibre des pouvoirs comme un idéal démocratique conduit cependant à postuler que ce paradigme à lui seul est incapable de saisir et de refléter la réalité phénoménale des rapports complexes qui se nouent et se dénouent entre les différents pouvoirs constitutifs d'un État même sous l'égide de la démocratie libérale. À contre-courant de la doctrine classique qui érige le dogme politico-juridique de l'équilibre, l'observateur averti opposera le contreparadigme empirique du déséquilibre des pouvoirs observable dans tout régime politique se revendiquant démocratique, et ce avec une prégnance du pouvoir judiciaire au nom de l'État de droit (2.3). Il en va ainsi dans les régimes parlementaires et présidentiels où l'on observe tour à tour une certaine dominance du pouvoir législatif (2.2) et prédominance du pouvoir exécutif (2.1).

\subsection{La suprématie du pouvoir exécutif dans les régimes présidentiels}

12 Le pouvoir exécutif doit être entendu ici non pas au sens classiquement large, mais davantage au sens strict de régime de gouvernement présidentiel, monocéphale - ayant à sa tête uniquement un président de la République (États-Unis, Turquie, Tchad, etc.) ou bicéphale - ayant à sa tête un président de la République assisté d'un Premier ministre (France, Cameroun, etc.) Par régime de type présidentiel, il convient de désigner primo le régime présidentiel traditionnel, secundo sa relative perversion qu'est le présidentialisme (démocratique) et tertio sa dérive autoritariste, l'hyperprésidentialisme (dictatorial) ${ }^{31}$. Dans le régime présidentiel traditionnel, caractéristique de certains pays occidentaux se réclamant des " démocraties évoluées " et ayant à leur tête un président de la République ou chef de l'État qui gouverne à l'instar des États-Unis et de la France (dans une certaine mesure), nonobstant une consécration constitutionnelle de l'équilibre des pouvoirs, le président reste tout de même dépositaire d'un pouvoir fort lui permettant, en temps normal comme de crise, d'orienter et d'infléchir la politique législative et judiciaire de la Nation. Garant de la constitution, du bon fonctionnement des institutions et de l'unité de l'État, il les incarne et exerce ipso facto et jure une influence considérable sur le pouvoir législatif et judiciaire en dépit de l'affirmation constitutionnelle, et l'ancrage institutionnel, de contre-pouvoirs. Dans sa relation avec le pouvoir législatif, le président peut être dépositaire d'un droit de veto sur toute nouvelle loi (cas des États-Unis ${ }^{32}$ ). Il peut aussi, sur autorisation du Parlement, pour une période limitée, empiéter sur le domaine de la loi qui est par tradition une compétence réservée du Parlement et légiférer par voie d'ordonnance ayant force de loi ou de décret (cas de la France) ${ }^{33}$. Même en cas de suspicion légitime, le Parlement ne peut constitutionnellement contraindre le président à s'expliquer devant lui. L'impuissance de la commission d'enquête 
parlementaire dans l'affaire Alexandre Benalla qui mit en cause le président Emmanuel Macron en constitue une illustration significative.

En France, cette dominance de l'exécutif dans ses rapports avec le législatif se révèle notoirement au travers du très controversé article 49-3 de la Constitution qui permet au gouvernement sous l'impulsion du Premier ministre de faire adopter une loi sans discussions et/ou accord parlementaires ${ }^{34}$. Le régime présidentiel ou semi-présidentiel, tout comme certains régimes parlementaires, lorsqu'ils sont confrontés à une instabilité chronique du gouvernement, débouche très souvent sur l'initiative de réforme constitutionnelle, voire de réforme du système électoral par le gouvernement en vue d'instaurer une forme de "parlementarisme rationalisé». À terme, le parlementarisme rationalisé déséquilibre les pouvoirs et renforce le pouvoir du gouvernement au détriment du parlement ${ }^{35}$. Il conduit ainsi à une séparation dite perméable des pouvoirs au profit de l'exécutif. Les pouvoirs du Parlement y sont tempérés (rationalisation technique par constitutionnalisation) dans le but de donner une grande stabilité au gouvernement notamment par la mise en place des majorités parlementaire et présidentielle (rationalisation politique par codification électorale) et de limiter, autant que faire se peut, la mise en cause de sa responsabilité (motion de censure) et son renversement par le Parlement ${ }^{36}$. Dans un régime présidentiel et surtout présidentialiste, les cas d'ouverture d'une procédure de destitution du président de la République (impeachment), de renversement du gouvernement ou de déchéance de certains de ses membres éminents par le Parlement sont strictement réduits par la constitution au travers d'un formalisme procédural fort pesant. La France, les États-Unis dans une moindre mesure et surtout le Cameroun en sont des exemples.

Dans sa relation avec le pouvoir judiciaire que l'on dit indépendant, le pouvoir exécutif, en particulier le président, exerce une forte emprise. Il nomme les hauts emplois judiciaires et surtout les magistrats du parquet et les juges de la Cour suprême (ÉtatsUnis) ou encore de la juridiction constitutionnelle (Cameroun). L'équilibre des pouvoirs est d'autant plus biaisé que le pouvoir judiciaire fait institutionnellement partie intégrante de l'exécutif sous la houlette d'un ministre de la Justice, membre du gouvernement sous l'autorité du président de la République. En France, outre le pouvoir du président de la République de nommer le tiers des 9 membres de principe du Conseil constitutionnel, dont son président qui a une voix prépondérante en cas de partage de vote, tous les anciens présidents de la République, dès la cessation de leur fonction, deviennent, sauf renonciation, membres d'office et à vie du Conseil constitutionnel ${ }^{37}$. Plus remarquable encore, malgré la consécration constitutionnelle de l'équilibre des pouvoirs et de la soumission du gouvernement au droit, nombre de prérogatives sont reconnues au gouvernement, permettant à son action d'échapper au contrôle du pouvoir judiciaire et même de passer outre son autorité et d'interférer dans son fonctionnement. Il en va ainsi de l'immunité inconditionnelle accordée au président de la République dans le cadre de ses fonctions. En droit administratif français et de l'Afrique francophone, de la théorie des "actes de gouvernement" insusceptibles de tout recours devant une juridiction comme : la décision du président de promulguer ou non une loi; d'engager ou de retirer le pays d'un traité international; de décréter ou non l'état d'urgence ou d'exception (état de siège, de crise ou de calamité); de déclarer la guerre, supposée se faire en principe sur autorisation du Parlement, mais dont le président s'arroge très souvent l'initiative. La 
disposition d'un droit de grâce et d'amnistie par le président de la République, le droit pour le ministre de la Justice, garde des Sceaux, d'arrêter des poursuites pénales à l'encontre d'un délinquant dans l'intérêt de l'ordre public constituent autant de symptômes d'une emprise de l'exécutif sur le judiciaire et donc d'un déséquilibre palpable des pouvoirs en contexte de démocratie libérale.

Le présidentialisme démocratique est quant à lui marqué par une rupture nette, quoique souvent occasionnelle, de l'équilibre des pouvoirs en faveur de l'exécutif et notamment du président de la République au détriment des autres pouvoirs. Il se révèle habituellement en situation de crise dans les régimes présidentiels traditionnels où l'exécutif, voire le président de la République, est déjà détenteur de très larges pouvoirs. Il en va ainsi lorsqu'il outrepasse, au nom de l'état d'urgence, d'exception, de guerre ou encore du maintien de l'ordre public, ses pouvoirs traditionnels, quitte à empiéter sur le domaine du pouvoir législatif et à mettre en péril l'État de droit ainsi que les droits et libertés des personnes. Entre le régime présidentiel et le présidentialisme, il n'y a bien souvent qu'un pas pour franchir l'allège que l'on soit en temps normal ou en temps de crise. La France a vécu le présidentialisme notoirement sous l'ère de Gaulle, avec les guerres d'indépendances, Sarkozy, Hollande, au lendemain des attentats terroristes de Paris et de Nice, et Macron, depuis l'aggravation de la crise sanitaire liée à la pandémie du Covid-19. Mais, en réalité, la sociogenèse de la République française démontre, exception faite des éphémères gouvernements successivement instables (semi-parlementaire ou mixte) de la IV ${ }^{e}$ République, qu'elle a historiquement navigué entre le régime présidentiel - dans une moindre mesure - et le présidentialisme ( $V^{e}$ République), voire l'hyper-présidentialisme (de la monarchie à la III République) avec un affaiblissement notable du Parlement ${ }^{38}$. Les États-Unis, contrairement à la France, restent un régime présidentiel traditionnel, avec une propension semi-présidentielle par le renforcement circonstanciel, par activisme, des pouvoirs du Congrès ${ }^{39}$, ce que le président Woodrow Wilson qualifia de " gouvernement congressionne $\mathrm{l}^{40}$ ». Quelques soubresauts présidentialistes sont toutefois à noter sous les présidences de Woodrow Wilson (1913-1921), Franklin D. Roosevelt (1933-1945), suite au déclenchement des deux guerres mondiales, ou encore de Georges W. Bush (2001-2009), au lendemain des attentats du 11 septembre 2001, lorsqu'ils avaient adopté le Patriot Act dont certaines dispositions (notamment les sections 213, 215, 412, 802, etc.) autorisent les perquisitions sans mandat de justice, le contrôle systématique des communications électroniques, la surveillance de masse, etc. Ces mesures, jugées inconstitutionnelles et attentatoires aux libertés fondamentales au regard des $1^{\mathrm{er}}, 4^{\mathrm{e}}, 5^{\mathrm{e}}$ et $6^{\mathrm{e}}$ amendements de la constitution américaine, étendaient anormalement les pouvoirs du gouvernement en matière de lutte contre le terrorisme $e^{41}$.

16 Enfin, l'hyper-présidentialisme dictatorial ou monocentrisme présidentiel est un régime politique autoritariste caractéristique des États postcoloniaux notamment d'Afrique, d'Amérique latine et du Moyen-Orient où il n'existe en pratique aucune séparation et encore moins un équilibre des pouvoirs au-delà de l'esprit et de la lettre de la constitution ${ }^{42}$. L'actualité politique brûlante de la Turquie offre d'emblée un exemple fort évocateur depuis le putsch manqué dans la nuit du 15 au 16 juillet 2016 contre le gouvernement jugé autoritaire ${ }^{43}$ de Binali Yildirim alors Premier ministre sous l'influence du président de la République Recep Tayip Erdogan. Le putsch aura servi d'argument d'autorité pour légitimer la controversée réforme constitutionnelle adoptée par la grande Assemblée nationale de Turquie le 21 janvier 2017 et entérinée par voie référendaire le 16 avril $2017^{44}$. Entre autres objectifs louables tels que la 
constitutionnalisation de l'impartialité de la magistrature (art. 9) et l'abaissement de l'âge d'éligibilité à la députation de 25 à 18 ans (art.76), la réforme vise surtout à présidentialiser le régime politique turc jusque-là parlementaire, puisque peu de pouvoirs étaient attachés à l'ancienne fonction honorifique d'un président de la République sans mandat politique et encore moins de pouvoir exécutif. Par la suppression de la fonction de Premier ministre, autrefois instance suprême au sein du pouvoir exécutif et son remplacement par un vice-président nommé et révocable par le nouveau président de la République devenu chef suprême de l'exécutif (art. 9 et 104), elle confère quasiment les pleins pouvoirs à ce dernier, en consolidant son emprise sur les pouvoirs judiciaire et législatif. Le présidentialisme étant a priori un régime politique compatible avec l'idéal démocratique de l'équilibre et de la séparation des pouvoirs au sein de l'État, ce n'est pas tant la présidentialisation du régime politique turc qui interroge, mais bien l'effritement de la consistance démocratique qui en résulte du fait du déséquilibre croissant des pouvoirs ou de leur forte influence par le président Recep Tayip Erdogan. C'est aussi la potentielle instrumentalisation des pouvoirs législatif et surtout judiciaire qui interpelle les observateurs avertis au lendemain du putsch manqué où le régime turc est soupçonné, non sans raison, d'autoritarisme.

17 S'agissant du déséquilibre des pouvoirs et parallèlement à l'indépendance de la justice, la nouvelle constitution consacre l'intervention proactive du président, en concurrence avec l'Assemblée nationale, dans le processus de nomination des membres de la cour constitutionnelle et du Haut conseil des juges et procureurs (HSYK), équivalent du Conseil supérieur de la magistrature, chargé d'investir et de destituer les magistrats. Le président dispose du pouvoir de nommer 12 des 15 membres du Conseil constitutionnel contre 3 pour l'Assemblée nationale et 6 des 13 membres du HSYK contre 7 pour l'Assemblée nationale (art. 159); le ministre de la Justice et son vice-ministre étant membres de droit et donc nommés de facto par le président de la République. La Cour de cassation, le Conseil d'État, l'Académie de justice, les juges et procureurs en exercice perdent par voie de conséquence le droit d'élire une partie de leurs pairs censés les représenter au HSYK. Le déséquilibre des pouvoirs en l'espèce réside moins dans le pouvoir de nomination des magistrats par le président de la République que dans l'absence totale de contrôle parlementaire par approbation ou réprobation comme c'est le cas aux États-Unis. Or, un tel contrôle a posteriori du Parlement est un gage d'équilibre et de contre-pouvoir en cas d'abus du président. Le déséquilibre des pouvoirs se corse davantage dans un Parlement turc monocaméral éventuellement ou potentiellement acquis à la majorité présidentielle où la possibilité de le mettre en accusation par $3 / 5^{\mathrm{e}}$ des membres peut vite devenir illusoire. Ce d'autant plus que le président de la République dispose non seulement du droit de dissoudre l'Assemblée nationale afin de prévenir une cohabitation conflictuelle avec le gouvernement (art. 116), mais aussi d'un droit de veto sur les lois adoptées par elle (art. 89).

$18 \mathrm{Au}$ soutien de la réforme, les réformateurs ont avancé deux principaux arguments de nécessité. D'une part, la nécessité de consolider le régime politique face au risque d'instabilité gouvernementale lié au potentiel conflit de compétence et de légitimité entre le Premier ministre simplement issu de la majorité parlementaire et le président de la République directement élu au suffrage universel. D’autre part, la nécessité de restaurer durablement l'autorité de l'État face au risque d'instabilité politique inhérent à la difficile constitution d'une majorité parlementaire. Un risque d'instabilité lié en partie à l'activisme politique des mouvements dissident et séparatiste (FETO, PKK, etc.), 
doublé d'un risque d'insécurité accentué par leur activisme militaire. Mais l'opposition y a plutôt perçu l'aboutissement d'une dérive autoritaire. En effet, il est constant dans l'histoire de la Turquie moderne que l'exécutif, autrefois sous l'influence de l'armée, instrumentalise le pouvoir législatif et judiciaire. Un autoritarisme qui s'est accentué depuis 2003 avec l'accession à la primature de Recep Tahip Erdogan, actant ainsi la mort programmée de la séparation des pouvoirs par un renforcement de l'emprise de l'exécutif sur les institutions judiciaire et législative. En témoignent les purges observées dans toutes les sphères de la vie publique depuis le putsch manqué de juillet 2016, avec l'assentiment tacite d'une Assemblée nationale impuissante, si ce n'est la coaction d'une justice expéditive aux ordres de l'exécutif. Pour nombre d'observateurs avertis, le nouvel ordre constitutionnel turc vient ainsi consolider le tournant «pouvoiriste » du régime en place dans son entreprise de construction d'un hyper-présidentialisme aux relents monarchiques ${ }^{45}$.

Les régimes hyper-présidentialistes sont des systèmes politiques officiellement démocratiques (démocratie formelle), mais officieusement dictatoriaux (dictature réelle), d'où leur appellation, à juste titre par les socio-politologues, de " démocrature ${ }^{46}$ » (néologisme issu d'une fusion de "démocratie » et de "dictature »). Ils se singularisent par l'omnipotence et la magnificence du président de la République consacrées parfois dans la lettre de la constitution avec une vassalisation subséquente des pouvoirs législatif et judiciaire. Ceux-ci ne jouent bien souvent au sein de l'État qu'un rôle symbolique de figuration et d'accompagnement du tout puissant président dans sa politique totalitaire d'orientation et d'instrumentalisation des institutions de l'État. Le contrôle parlementaire et judiciaire de l'action du gouvernement y est synonyme de panurgisme. Le parti au pouvoir, du fait de sa position ultradominante et de sa surreprésentation au sein du Parlement et du pouvoir judiciaire, notamment au sein de la Cour suprême et de la juridiction constitutionnelle dont la nomination d'une partie des membres relève de la discrétion de l'hyper-président, rythme le quotidien des institutions « myopathiques » de l'État avec lequel il se confond (parti-État).

Dans les démocratures hyper-présidentialistes, le président de la République est président de tout. Le cas du Cameroun offre un exemple révélateur du constitutionnalisme africain qualifié, non sans raison, de "constitutionnalisme de figuration ${ }^{47}$ » qui, mis à l'épreuve de son application, constitue, aux dires de la doctrine, " une grande désillusion démocratique ${ }^{48}$ ». Outre les différents pouvoirs inhérents au régime présidentiel traditionnel susmentionné, la constitution ainsi que la pratique des institutions ${ }^{49}$ confèrent presque tous les pouvoirs au président de la République. Ce dernier mériterait bien le qualificatif de "monarque constitutionnel ». Il définit la politique de la Nation, veille au respect de la constitution, à l'indépendance de la justice et assure, par son arbitrage, le fonctionnement des institutions y compris l'autorité judiciaire et le Parlement dont les missions constitutionnelles restent une illusion aux yeux d'un observateur averti de la scène politique ${ }^{50}$. Il est président du Conseil supérieur de la magistrature, président du Conseil économique et social et a autorité pour nommer ou révoquer les membres de la haute hiérarchie de tous les organismes « indépendants » ou censés l'être au sein de l'État tels que la Commission nationale électorale, le Conseil national de la communication, le Contrôle supérieur de l'État, la Commission nationale des droits de l'homme et libertés publiques, etc. Ces organismes indépendants sont pourtant présentés dans la théorie postmoderne et matérielle de la séparation des pouvoirs comme le quatrième pouvoir parmi d'autres ${ }^{51}$. 
21 Le président de la République du Cameroun a constitutionnellement le droit en temps de crise d'abréger ou de proroger sans élection le mandat de l'Assemblée nationale en deçà et au-delà de la législature, de nommer en temps normal un tiers des sénateurs ${ }^{52}$, etc. Il ne peut être mis en accusation par le Parlement que moyennant un vote identique au scrutin public et à la majorité des quatre cinquièmes des membres. Il peut se représenter autant de fois qu'il le souhaite aux élections présidentielles, et donc être président à vie ${ }^{53}$. Par voie de conséquence, les « pouvoirs judiciaire et législatif » sont aux ordres du président de la République. En témoigne entre autres la fameuse « opération Épervier », similaire à l'« opération Cobra » depuis 2012 au Tchad, lancée depuis les années 2000 au nom de la lutte contre la corruption, qui s'est avérée être, selon certains observateurs, un redoutable instrument de répression politique ${ }^{54}$. Le Parlement camerounais, qualifié de "chambre d'enregistrement des "hautes instructions du président de la République" ", pour reprendre une expression populaire dans les médias camerounais, est réputé tant pour son mutisme dans le contrôle de l'action du tout puissant gouvernement que son manque d'initiative en matière de propositions de loi. Tel est en substance l'hyper-présidentialisme révélateur de la concentration et du déséquilibre des pouvoirs qui ressortent de la lettre de la constitution de la République du Cameroun du 2 juin 1972 telle que successivement modifiée par les lois constitutionnelles $n^{\circ}$ 96/06 du 18 janvier $1996^{55}$ et $n^{\circ} 2008 / 1$ du 14 avril 2008 ayant eu pour principal effet pervers une certaine monarchisation du système politique camerounais. Un système politique à l'image de la plupart de ceux des États de l'Afrique francophone qui assume mal le mimétisme constitutionnel et dénature par voie de conséquence l'héritage constitutionnel pourtant démocratique de la France.

L'hyper-présidentialisme constitutionnel est ainsi devenu une marque de fabrique des régimes politiques francophones subsahariens dont les chefs d'État dans l'histoire postcoloniale sont reconnus pour exercer ou conserver le pouvoir au-delà de la dévolution constitutionnelle ou du mandat constitutionnel. Et ce avec la bénédiction des pouvoirs législatif et judiciaire inféodés à l'exécutif et acquis généralement au parti au pouvoir faisant office de parti-État. L'actualité politique des pays d'Afrique francophone le démontre à suffisance une fois encore à travers des illustrations significatives qui repoussent les limites de l'hyper-présidentialisme constitutionnel. Le Tchad, par exemple, où le gouvernement, après avoir reporté sine die les élections législatives de 2016, prorogeant ipso facto et jure la législature pour une durée indéterminée, a opéré une réforme constitutionnelle expéditive, par voie parlementaire et non référendaire le 30 avril 2018 dans le but de renforcer et de perpétuer le pouvoir du président Idriss Déby Itno. S'inscrivant dans la lignée de la précédente réforme de 2005 ayant fait sauter le verrou de la limitation des mandats présidentiels, cette nouvelle constitution adoptée le 30 avril 2018 par le Parlement et promulguée le 4 mai 2018, assure au président tchadien aux rênes de l'État depuis 1990 d'y rester potentiellement jusqu'en 2033. Entre autres, elle supprime le poste de Premier ministre et accentue la concentration des pouvoirs au profit du président de la République. Dans un système où la séparation des pouvoirs ainsi que l'indépendance de la justice constitutionnelle, bien que consacrées par la constitution, ne sont point garanties dans la pratique institutionnelle ${ }^{56}$, l'adoption d'une nouvelle constitution par un Parlement acquis à la majorité présidentielle a suscité l'ire de l'opposition, des organisations de la société civile et de l'Église catholique revendiquant qu'elle aurait dû être soumise au référendum populaire ${ }^{57}$. Au Gabon, c'est la Cour constitutionnelle, 
passant outre la disposition pourtant claire de la constitution de 1991 prescrivant de nouvelles élections présidentielles en cas de vacance de toute nature de la présidence de la République, qui a procédé indûment à une révision constitutionnelle soi-disant " provisoire " par décision de justice en autorisant le vice-président à assurer l'intérim. Or, l'article 14e de la constitution gabonaise (par ailleurs en cours de modification au Parlement) prévoit que «Les fonctions de Vice-Président de la République cessent à l'issue de la proclamation des résultats de l'élection présidentielle par la Cour constitutionnelle et en cas de vacance de la Présidence de la République pour quelque cause que ce soit ou d'empêchement définitif du Président de la République». L'article 13 précédent prévoit en outre que le président du Sénat doit assurer l'intérim et organiser de nouvelles élections, sauf cas de force majeure, dans les 60 jours suivants la vacance de la présidence. Il s'agit donc d'une « violation en règle » de la constitution par la Cour constitutionnelle dont la mission première est pourtant d'en assurer le respect. Le but inavoué de la manœuvre de la cour inféodée à l'exécutif et présidée par ailleurs par la belle-mère du président Ali Bongo Ondimba étant de le maintenir au pouvoir; pourtant il en est empêché par un accident vasculaire cérébral qui l'a contraint à une hospitalisation depuis le 24 octobre 2018 à Riyad, puis à Rabat d'où il a hâtivement regagné Libreville suite au putsch manqué du 7 janvier 2019 pour présider le 15 janvier en fauteuil roulant l'investiture expéditive à huis clos du nouveau gouvernement et repartir le lendemain à Rabat. Une mise en scène rocambolesque que l'opposition a qualifiée de "théâtralisation des institutions ${ }^{58}$ ". Au Cameroun où la commission nationale électorale, Elections Cameroon et le jeune Conseil constitutionnel mis en place en février 2018 - composé majoritairement d'anciens membres officiellement bien connus du parti au pouvoir, le RDPC, nommés par le président Paul Biya avec le concours passif du Parlement et d'un Conseil supérieur de la magistrature sous son autorité, membres dont les noms figuraient encore à la veille de l'élection présidentielle du 7 octobre 2018 sur le site officiel du parti - ont validé les résultats des élections pourtant jugées non transparentes et partiales par la communauté internationale au regard des fraudes et violences massives ayant émaillé le scrutin, avec l'appui des forces armées soutenant le gouvernement sortant. Des manquements constitutionnels qui ont conduit l'opposition à contester les résultats de même que l'impartialité des juges constitutionnels devant le Conseil qui, refusant de communiquer les procès-verbaux au prouvant la victoire du parti au pouvoir, leur a opposé une irrecevabilité tant sur la forme (récusation des juges) que sur le fond. La contestation a d'ailleurs conduit à une grave crise postélectorale ${ }^{59}$, non encore soldée devant la Cour africaine des droits de l'homme et des peuples où ni le gouvernement ni la commission électorale n'a pu produire les procès-verbaux litigieux malgré les injonctions de la cour. Comment aurait-on pu s'attendre à une justice constitutionnelle indépendante et impartiale lorsque la quasi-totalité des juges constitutionnels furent des membres du comité central du parti au pouvoir et que les épouses du président du Conseil et de l'un de ses membres sont actuellement des députées de ce même parti, partie au contentieux électoral? Il va sans dire que dans ce contexte de contraintes politico-institutionnelles et surtout de potentiels conflits d'intérêts le Conseil constitutionnel camerounais fut juge et partie au contentieux de l'élection présidentielle. Comment aurait-il pu en être autrement dans un régime politique conférant constitutionnellement la mainmise à l'exécutif sur les pouvoirs législatif et judiciaire? Comment peut-on s'attendre à une séparation des pouvoirs lorsque le président de la République du Cameroun sans contrôle parlementaire a priori ou a 
posteriori nomme tous les membres de la Cour suprême et du Conseil constitutionnel ainsi qu'un tiers des sénateurs d'un Parlement déjà largement acquis à la majorité présidentielle? Comment parler en définitive d'équilibre des pouvoirs dans de tels régimes politiques qui sont pourtant, officiellement, des démocraties libérales? Une analyse objective recommande de distinguer à ce titre une démocratie formelle consacrant une concentration des pouvoirs au profit de l'exécutif, qui peut s'avérer foncièrement dictatoriale, d'une démocratie réelle ou matérielle de facture libérale garantissant potentiellement une séparation et un équilibre des pouvoirs au sein de l'État. La primauté du pouvoir exécutif caractéristique des régimes hyperprésidentialistes ne constitue pourtant que la partie visible de l'iceberg, "l'arbre qui cache mal la forêt » du déséquilibre des pouvoirs en contexte de démocratie libérale d'autant plus qu'un tel déséquilibre est aussi perceptible dans une moindre mesure dans les régimes parlementaires.

\subsection{La précellence du pouvoir législatif dans les régimes parlementaires}

Du point de vue de la légitimité démocratique et de la représentativité populaire, le pouvoir législatif est sans nul doute le pouvoir suprême qui devrait primer sur tous les autres dans la sphère étatique. Il n'est donc guère surprenant que dans un régime politique de type parlementaire, et sa perversion le parlementarisme, une certaine précellence du pouvoir législatif, incarné par le Parlement en principe bicaméral, sur les autres pouvoirs issus essentiellement des nominations, soit observable au sein de l'État. D'aucuns soutiennent que c'est la vocation ou la prédestination normale de toute démocratie populaire étant donné que seul le Parlement élu en tant qu'institution émanant entièrement de la volonté du peuple peut se réclamer d'une suffisante légitimité démocratique.

24 Le régime parlementaire trouve ses origines dans le royaume de Léon au XII ${ }^{\mathrm{e}}$ siècle, mais il faudra, pour sa véritable consécration, attendre le crépuscule du $\mathrm{XVIII}^{\mathrm{e}}$ siècle au Royaume-Uni où la souveraineté sera exercée concurremment par le monarque et le Parlement (régime parlementaire bicéphale ou dualiste ${ }^{60}$ ) avant d'aboutir progressivement à un effacement total du premier au profit de la toute-puissance du second (parlementarisme monocéphale ou moniste). On retrouve son application variable aujourd'hui dans nombre de démocraties occidentales et orientales (Allemagne, Canada, Espagne, Italie, Belgique, Grèce, Japon, Corée du Sud, Inde, etc.) En dépit de l'indépendance du pouvoir judiciaire, le régime parlementaire se caractérise par un renforcement des pouvoirs en principe législatifs du Parlement qui exerce une grande influence sur le gouvernement issu de la majorité parlementaire et politiquement responsable devant lui. Le Parlement, qui exerce un contrôle accru et inquisitoire sur l'action du gouvernement par le biais des questions, commissions et résolutions parlementaires, est ainsi doté de la faculté de le renverser presque ad nutum. En témoigne le récent renversement expéditif du gouvernement de Mariano Rajoy par le Parlement espagnol à la suite d'une motion de censure et, dans une moindre mesure, la non-investiture par le Congrès des députés du gouvernement minoritaire de son successeur Pédro Sánchez contraint de convoquer de nouvelles élections anticipées. Dans ce sillage, le Parlement peut s'octroyer le droit de ratification ou non d'un traité ou d'une convention internationale signée par le gouvernement ; sa 
décision échappant totalement au contrôle du pouvoir judiciaire. Le Parlement peut également paralyser l'action du gouvernement à travers divers mécanismes. L'exemple $\mathrm{du}$ Brexit en constitue une illustration, à travers le bras de fer opposant le gouvernement et le Parlement britannique remporté jusqu'ici par ce dernier suite à de nombreux revers: la décision de la Cour suprême dans les arrêts Miller (2017 ${ }^{61}$ et 201962); l'adoption d'une résolution parlementaire obligeant le gouvernement de Theresa May à soumettre au Parlement tout accord avec l'Union européenne sur les modalités de sortie du Royaume-Uni; l'adoption d'une autre résolution, récente, obligeant le gouvernement de Boris Johnson à solliciter un report. Elle offre à n'en point douter, une illustration du principe de la suprématie du Parlement, non pas seulement en droit constitutionnel britannique, mais aussi dans tout régime parlementaire. Le déséquilibre subséquent des pouvoirs s'en trouve davantage accru en cas de dérive contestataire de l'action du gouvernement par les parlementaires. La confrontation se solde habituellement par une instabilité chronique du gouvernement comme ce fut le cas durant la crise économique en Italie, en Belgique, en Espagne et en Grèce d'où la nécessaire limitation en pratique des pouvoirs du Parlement par une rationalisation technique et politique (parlementarisme rationalisé). Historiquement, le parlementarisme reste conjoncturel et ne s'observe généralement qu'à l'occasion de graves crises sociale et économique. Au même titre que les régimes présidentialistes, il démontre à suffisance, quoique de façon contextuelle et occasionnelle, le déséquilibre des pouvoirs au profit du Parlement dans les démocraties libérales. Un déséquilibre des pouvoirs qui bascule presque toujours, en dernier ressort, au profit du pouvoir judiciaire par l'affirmation de l'État de droit.

\subsection{La primauté ultime du pouvoir judiciaire dans l'État droit}

Au-delà de l'idéal dogmatique de l'équilibre des pouvoirs, il n'en demeure pas moins qu'une certaine primauté du pouvoir judiciaire incarnée en dernier ressort par la juridiction constitutionnelle reste observable dans toute démocratie libérale ou État de droit. Si l'État de droit signifie a priori la soumission de l'État au droit, il marque a posteriori la soumission des pouvoirs de l'État et donc des pouvoirs législatif, exécutif et judiciaire au droit incarné par le pouvoir judiciaire symbolisé lui-même par la juridiction constitutionnelle, organe régulateur suprême $d u$ fonctionnement des institutions. Cette dernière est chargée en dernier ressort non seulement du contrôle de la législation du Parlement et de l'action du gouvernement, mais surtout du contrôle de l'équilibre des pouvoirs, voire de la régulation ou répartition a posteriori des compétences entre les différents pouvoirs conformément à la loi fondamentale qu'est la constitution ${ }^{63}$. Par cohérentisme, du point de vue de la pure logique formelle (logique mère du droit, voire logique du sens et du raisonnement), il s'agit en dernière analyse, de la soumission des deux autres pouvoirs au pouvoir judiciaire. L'on pourra rétorquer que ce droit auquel se soumettent tous les pouvoirs, y compris le pouvoir judiciaire, juge en dernier ressort de cette soumission des pouvoirs de l'État au droit, est décidé principalement par le pouvoir constituant qui établit la constitution, le pouvoir législatif qui fait œuvre de loi et accessoirement par le pouvoir exécutif qui y concourt par l'exercice du pouvoir réglementaire et l'exécution de la loi ${ }^{64}$. Mais, ce serait vite aller en besogne et mésestimer les réalités pratiques du droit, notamment de son interprétation et de son application en sous-estimant le pouvoir créateur du droit du pouvoir judiciaire, c'est-à-dire le pouvoir en principe interprétatif, mais en pratique 
normatif ou normateur du juge notamment constitutionnel ${ }^{65}$, qui du fait de l'abstraction et de la généralité de la loi, est souvent considéré, à juste titre et en dernier ressort, comme le « véritable législateur ${ }^{66}$ » ou, tout du moins, le législateur des cas particuliers, pour reprendre une formule chère à Portalis et Planiol, couramment attribuée au doyen Ripert ${ }^{67}$. Le pouvoir de l'interprétation potentiellement créatrice de nouvelles normes par le juge constitutionnel, juge suprême de l'ordre juridique, est assez illustratif. C'est d'ailleurs pour cela que Hans Kelsen recommandait de limiter législativement le contrôle de constitutionnalité au strict minimum, voire de l'interdire lorsqu'il s'agit des préambules ou déclarations de droits trop vagues ou encore de soumettre la nomination des juges constitutionnels à la discrétion du Parlement ${ }^{68}$. Le but de cette opération de limitation ou de légitimation parlementaire de la création du droit par le juge constitutionnel, extensible ou valable en matière d'interprétation de toute norme juridique trop générale et abstraite qui augmente en pratique le pouvoir du juge, étant en définitive de rééquilibrer les rapports entre le pouvoir judiciaire et le pouvoir législatif qui devrait, en principe, être le seul à exercer le pouvoir de création du droit par sa grande légitimité démocratique tenue du peuple souverain. Kelsen préfère ainsi la délégation procédurale et démocratique par le Parlement du pouvoir normatif au juge plutôt que son usurpation par ce dernier à travers le jeu complexe de l'interprétation.

$\mathrm{La}$ " vérité juridique » ou la réalité politique qui contredit l'imaginaire démocratique et fait autant peur aux autres pouvoirs législatif et exécutif, c'est que "[l]'art de l'interprétation recèle donc un pouvoir, une puissance que l'idée de l'État de droit, dans lequel les décisions doivent être fondées en droit, refoule ${ }^{69}$ ». Toute vérité ne serait donc pas bonne à dire ou à établir même dans un État dit de droit au risque de briser le mythe ou l'idéal démocratique de l'équilibre des pouvoirs et de déstabiliser l'ordre étatique "démocratiquement » établi : veritas odium parit. Mieux vaut donc donner le faux sentiment enchanteur, l'illusion démocratique d'un équilibre que de dire la vérité de la pratique judiciaire ou la réalité politique du déséquilibre qui pourrait engendrer une guerre intestine et fratricide entre les différents pouvoirs au sein même de l'État de droit. Pourtant dans un État dit de droit, les sujets de droit n'ont-ils pas droit à la vérité?

Le contrôle de la cohérence des normes ou plus concrètement le contrôle de constitutionnalité, sanctionnateur de la conformité à la constitution de la loi ou de l'œuvre et de l'exercice du pouvoir législatif, que ce soit par voie d'exception ou plus significativement par voie d'action, ainsi que le contrôle de la légalité, sanctionnateur de la conformité à la loi de l'action du gouvernement ou de l'exercice du pouvoir exécutif, marquent, ainsi, dans les démocraties libérales et néolibérales, une certaine emprise, voire la primeur du pouvoir judiciaire sur les pouvoirs exécutif et législatif au nom de la primauté du droit et de l'État de droit. Mais cette primauté du droit et de l'État de droit n'est rien d'autre que celle du pouvoir judiciaire sur les autres pouvoirs contrôlés et censurés le cas échéant par lui. Dans la sociohistoire de l'État de droit, la doctrine, depuis Édouard Lambert, qualifie cette perversion judiciaire du jeu institutionnel de « gouvernement des juges ${ }^{70} »$ ou encore prosaïquement d' ' activisme judiciaire» notamment lorsque le pouvoir judiciaire poussait son contrôle sanctionnateur à son paroxysme ${ }^{71}$, en tentant de "légiférer et de gouverner par voie de décision de justice ${ }^{72}$ ", en s'ingérant de façon politicienne dans l'adoption des lois par le Parlement et leur mise en œuvre par le gouvernement. En témoignent de façon 
spectaculaire les récentes suspensions quoique provisoires des décrets antiimmigration du gouvernement de Donald Trump pour violation de la Constitution par les juges fédéraux américains notamment des tribunaux et cours fédérales d'appel (Seattle, San Francisco, New York, Maryland, Hawaï, etc.) et plus largement le retrait pur et simple des lois jugées inconstitutionnelles, bien que parfois justes ${ }^{73}$, à la suite de décisions des juridictions constitutionnelles à travers le monde. Que dire du pouvoir quasi inébranlable dont disposent les juridictions suprêmes dans une démocratie libérale de fixer l'état des mœurs et de la société sur telle ou telle question économique, sociale, politique ou culturelle, très souvent au gré des penchants, voire des dictats conservatistes ou progressistes des juges maquillés au nom du droit? L'on objectera sans doute que ces juges judiciaires, administratifs et constitutionnels sont nommés par l'exécutif, quelques fois avec l'assentiment du Parlement et que cela se fait, bien sûr, au nom du droit (constitution, traités, lois, etc. adoptées par le peuple ou le Parlement, ratifiés et promulgués par le gouvernement) ${ }^{74}$. Mais en réalité, que dire de leur immunité judiciaire de principe dans tous les systèmes juridiques, de la perpétuité de leur fonction et de leur inamovibilité comme c'est le cas pour les juges de la Cour suprême des États-Unis? De quelle emprise, et de quels contrôle ou contre-pouvoirs disposent les autres pouvoirs sur le pouvoir judiciaire une fois en fonction et en action $^{75}$ ? En l'espèce, il serait quelque peu candide de ne pas y voir un certain déséquilibre, du moins, contextuel des pouvoirs au profit du pouvoir judiciaire si ce n'est sa relative primeur sur les autres pouvoirs en démocratie libérale. Le sacro-saint principe constitutionnel de l'indépendance de la justice et du pouvoir judiciaire incarné en dernier ressort par le juge constitutionnel sonne ainsi comme une surenchère symbolique ou idéologique de la primeur du pouvoir judiciaire par rapport aux autres pouvoirs dans tout État de droit.

C'est au regard de tout ce qui précède qu'il est permis de constater à la suite de Charles Eisenmann que, nonobstant la croyance communément reçue de la théorie constitutionnelle de la séparation des pouvoirs, cette séparation et donc son corollaire l'équilibre des pouvoirs renvoie, somme toute, à une conception idéaliste et erronée du constitutionnalisme contemporain. Car, souligne-t-il, aucune constitution n'entérine, en dernière analyse au regard des contre-pouvoirs, l'interpénétration des pouvoirs qu'elle confère et de la pratique institutionnelle, une réelle séparation fonctionnelle et encore moins matérielle des pouvoirs au sein de l'État ${ }^{76}$. Au-delà même de l'impossible séparation et équilibre des trois pouvoirs traditionnels de l'État, il existe une autre forme de concentration des pouvoirs, autrement appelée cumul de mandats ou de fonctions, certes de plus en plus atténuée ou récusée tant par le système des incompatibilités que la clameur populaire, qui reste interne à chaque pouvoir traditionnel et constitue à la fois une pratique et un tabou dans les démocraties libérales et pseudo-libérales ${ }^{77}$.

\section{Conclusion}

Resituer l'équilibre des pouvoirs de l'idéalité à la réalité. Tel était le substrat de cette analyse métajuridique afin de déconstruire l'idéal dogmatique, voire «le mythe de la séparation et de l'équilibre des pouvoirs ${ }^{78}$ » et de reconstruire la réalité politique de la " collaboration ${ }^{79}$ et du déséquilibre des pouvoirs" observable en contexte de démocratie libérale. Le déséquilibre objectif et contextuel des pouvoirs qui émane de ce 
constat empirique résulte tantôt d'une quête de stabilité du gouvernement ou d'un abus de pouvoir (régime présidentiel et présidentialiste) ou encore d'une affirmation de la primauté et de la légitimité populaire du Parlement (régime parlementaire et parlementariste), tantôt d'une nécessaire soumission de tous les pouvoirs au droit comme seule garantie d'un État de droit et de liberté. La nécessaire soumission de l'État ou de ses différents pouvoirs au droit institue donc un certain déséquilibre au profit du pouvoir judiciaire incarné par les juridictions constitutionnelles. À l'analyse, il n'en demeure pas moins en théorie que la soumission de tous les pouvoirs au droit soit la meilleure garantie de leur équilibre idéal ${ }^{80}$, quoiqu'inaccessible, puisqu'a priori, seul le droit et donc l'État de droit s'en trouvent consolidés et superposés et non tel pouvoir au détriment de tel autre; le pouvoir judiciaire devant lui-même se soumettre au droit ${ }^{81}$. L'idéaltype n'est-il pas d'ailleurs qu'une utopie réflexive qui aide le sujet connaissant à penser, à comprendre et à théoriser le monde empirique rendu inaccessible par sa complexité phénoménale ? De ce point de vue, la séparation et l'équilibre des pouvoirs ne sont qu'un moyen pour l'imaginaire juridique et politique (la dogmatique constitutionnelle et démocratique) de mettre de l'ordre dans le désordre de l'articulation floue, de la collaboration complexe et du déséquilibre inconstant des pouvoirs ${ }^{82}$. En tout état de cause, l'équilibre et la séparation des pouvoirs ne sont que des modèles idéaltypiques dont l'ancrage dans le réel reste en constant mouvement selon le régime politique et surtout le jeu de ses acteurs dans l'exercice des trois pouvoirs constitutifs de l'État postmoderne. Doit-on en conclure pour autant qu'il y aurait un certain équilibre du fait de ce déséquilibre inconstant et contextuel en faveur de tel ou tel pouvoir? Il serait dogmatique de répondre par l'affirmative parce qu'il y a bien un constat d'un réel déséquilibre à la fois du point de la logique du raisonnement et de la logique des faits, mais jamais d'équilibre au sens empirique de fixité et de stabilité. L'enjeu de l'idéal démocratique de l'équilibre et le jeu du déséquilibre des pouvoirs dans la réalité politique sont d'autant plus pervertis dans la contemporanéité postmoderne que l'on note l'entrée en scène d'organisations politiques communautaires anationales ou supranationales, l'État plurinational, multinational ou l'État-multination ${ }^{83}$ qui marquent le déclin de l'État-nation traditionnellement caractéristique de la démocratie libérale de type populaire vers des démocraties néolibérales de type technocratique à vocation fédérale ou confédérale. John Locke, l'un des maîtres penseurs de la séparation et de l'équilibre des pouvoirs, du libéralisme ${ }^{84}$ et de l'État de droit ne considérait-il pas que l'expérience est la seule source de connaissance? L'équilibre des pouvoirs ne peut être que déséquilibré en contexte de démocratie libérale! Et si déséquilibre il devrait y avoir, il doit être en faveur du pouvoir législatif qui incarne au mieux le pouvoir souverain du peuple.

\section{NOTES}

1. Charles Bastide, John Locke, ses théories politiques et leur influence en Angleterre, Paris, Leroux, 1906, p. 114. 
2. Ce texte fait suite à une réflexion dans le cadre d'un atelier interdisciplinaire de droit et de philosophie intitulé «L'équilibre des pouvoirs en contexte de démocratie libérale", tenu à l'Institut d'éthique appliquée de la faculté de philosophie de l'université Laval à Québec le 23 mai 2017.

3. John Locke, Traité du gouvernement civil, Londres, Amen-Corner, 1690. L'œuvre renvoie à deux traités sous les titres originaux de Two Treatises of Government, in the former the false Principles, and Fondation of Sr. Robert Filmer and his Followers are detected and overthrown et Essay concerning the true Origine, Extent and End of Civil Government.

4. La République, livre VIII, notamment 547 et 557 et suiv. (Robert Baccou trad., Paris, Garnier, 1936, http://remacle.org/bloodwolf/philosophes/platon/rep8.htm). Platon dépeint les formes de gouvernement notamment la démocratie basée sur une constitution qui garantit la liberté et le respect de la justice.

5. Les Lois, livre III, chap. XI, 693b et XIV, 698b, Victor Cousin (trad.), Paris, Picho, 1832, t. VIII, http://remacle.org/bloodwolf/philosophes/platon/loislivre3.htm : «[L]e législateur ne doit pas instituer d'autorité trop grande et qui ne soit pas tempérée [...] Quant au gouvernement de l'Attique, il nous faut maintenant le soumettre à son tour au même examen et prouver que la liberté intégrale, qui n'est soumise à aucun pouvoir, est bien loin de valoir un gouvernement modéré soumis à d'autres pouvoirs. »

6. Politique d'Aristote, $3^{\mathrm{e}}$ éd. Jules Barthélemy-Saint-Hilaire (trad.), Paris, Ladrange, 1874, livre VI, chap. VI, §1, http://remacle.org/bloodwolf/philosophes/Aristote/politique6.htm\#XI. Ainsi que le confirme le traducteur dès la préface : «Montesquieu doit beaucoup à ses devanciers, dont il fait parfois un bel éloge. Mais il est loin de savoir exactement tout ce qu'il leur doit; et son érudition, qu'on a trouvée si fréquemment en défaut, n'est pas en ceci non plus très complète. Aristote avait largement emprunté à Platon, le plus souvent sans le dire; mais il était son disciple; et de plus, il ne faisait pas œuvre d'érudit. Montesquieu n'a pas moins emprunté de Platon et d'Aristote; et s'il ne les a pas toujours nommés, c'est qu'il a ignoré plus d'une fois les sources où il puisait. Il faut même ajouter, pour être tout à fait juste, qu'il ne les a pas toujours entièrement comprises. Il y a vraiment quelque embarras à prononcer une sentence aussi sévère. Mais les droits de la vérité sont plus sacrés encore que ceux du génie; et Montesquieu lui-même devrait approuver cette franchise, qu'il nous pardonnera. Que l'on prenne, par exemple, la théorie des trois gouvernements. Il n'en est point de plus importante, non pas seulement pour la science en général, mais pour l'ouvrage de Montesquieu, tel que l'auteur lui-même l'a conçu. Cette théorie est parfaitement claire dans Platon. Elle est plus développée et plus simple encore dans Aristote, qui en a fait comme la trame de son livre, et a transmis ce fécond exemple à ses successeurs. » À quoi il ajoute, en commentaire du $1^{\text {er }} \S$ du chap. vi du livre 6 : «Voilà la théorie des trois pouvoirs, législatif, exécutif et judiciaire; il n'est pas besoin de la recommander à l'attention du lecteur. Montesquieu (livre XI, chap. VI) l'a un peu changée, et il a omis de rappeler qu'elle était due à Aristote. »

7. L'on constate que le pouvoir judiciaire ne figure pas dans le triptyque initialement établi par John Locke. En plus de l'exécutif et du législatif, il ressort le " pouvoir fédératif ou confédératif » qui renvoie au pouvoir qu'a un État d'établir les relations avec les autres sujets de droit international. Or, ce pouvoir international est du ressort de l'exécutif dans la théorie moderne de la séparation des pouvoirs. Cette négation du pouvoir judiciaire se justifie par la méfiance des théoriciens de l'époque vis-à-vis du juge et se retrouve notamment chez Montesquieu qui considère que « la puissance de juger est nulle », le juge n'étant qu'une «bouche servile de la loi » (Montesquieu, De l'esprit des lois, 1748, livre XI, chap. vI). Ce faisant, l'expression " "puissance" de juger» utilisée par Montesquieu dans sa rhétorique ne trahit-elle pas finalement son intention, voire sa contradiction avec la réalité de la fonction judiciaire ? Une " "puissance" de juger » ne peut en effet être « nulle», sauf à n'en point être. 
8. La démocratie est un régime politique au sein duquel le pouvoir appartient au peuple qui l'exerce à travers ses représentants élus. Du fait de son essence idéaltypique, elle est pluridimensionnelle: démocratie indirecte ou représentative (présidentielle, parlementaire, mixte ou semi-présidentielle), démocratie semi-directe (participative et délégative) ou semireprésentative, démocratie directe (aujourd'hui exceptionnelle et peu usitée), démocratie libérale ou occidentale, démocratie communiste, démocratie pluraliste ou multipartite, démocratie monopartite, démocratie populaire, démocratie sociale ou social-démocratie, démocratie chrétienne, démocratie formelle, démocratie réelle, etc.

9. La démocratie libérale encore appelée démocratie occidentale est une forme de gouvernement représentatif et idéologique fondé sur l'État de droit, la séparation des pouvoirs, l'alternance au pouvoir, le libéralisme, la protection des droits et libertés fondamentales de l'individu, du groupe et des minorités, etc.

10. L'idéaltype, notion tirée de la sociologie wébérienne, renvoie, tel un idéal vers lequel on tend, à un type abstrait, un concept, un modèle, une catégorie idéelle et idéale qui aide à faire penser un phénomène complexe sans toutefois être réductible à celui-ci. Il est en pratique inaccessible et recèle une dimension utopique, dogmatique et une valeur foncièrement opératoire et hypothétique. Voir Max Weber, Essai sur la théorie de la science, Julien Freund (trad.), Paris, Plon, 1965, en particulier le $1^{\text {er }}$ essai : "L'objectivité de la connaissance dans les sciences et la politique sociales (1904)», Québec, Université de Québec, 2006, p.68 et suiv., http:// classiques.uqac.ca/classiques/Weber/essais_theorie_science/Essais_science_1.pdf ; Jacques Coenen-Huther, "Le type idéal comme instrument de la recherche sociologique ", Revue française de sociologie, vol. 44, $\mathrm{n}^{\circ} 3,2003$, p. 531-547.

11. Sur la question en droit français, voir Michel Troper, La séparation des pouvoirs et l'histoire constitutionnelle française, Paris, LGDJ, 1973.

12. Un État de droit (Rule of law, ou Rechtsstaat) est un système institutionnel caractéristique de la démocratie libérale dans lequel l'État ou la puissance publique est soumise au droit au même titre que les gouvernants et les gouvernés. Toute action de l'État ou des individus en son sein est soumise au respect des normes juridiques (principe de la primauté du droit qui assure une sécurité juridique aux citoyens). L'État de droit est un idéaltype, un concept juridique, politique et philosophique qui s'oppose à l'État de non-droit, l'État de police, l'État de dictature, l'état de nature, etc. Voir Bernard Luisin, "Le mythe de l'État de droit", "L'État de droit, rétrospectivement..." ", Civitas Europa, vol. 37, n², 2016, p. 155-182; Jean Rivero, "L'État moderne peut-il encore être un État de droit? ", Annales de la Faculté de droit de Liège, 1957, p. 65-101.

13. Voir dans ce sens Chloé Mathieu, La séparation des pouvoirs dans la jurisprudence du Conseil constitutionnel, thèse, Université de Montpellier, 2015.

14. Avis $n^{\circ} 695 / 2012$ de la Commission européenne pour la démocratie par le droit (Commission de Venise) sur l'équilibre des pouvoirs dans la constitution et la législation de la Principauté de Monaco, p. 5.

15. Résolution des Nations unies A/RES/59/201 du 20 décembre 2004 relative au renforcement des organisations et mécanismes régionaux et sous-régionaux et autres en vue de promouvoir et de consolider la démocratie prise en application du Pacte international relatif aux droits civils et politiques du 16 décembre 1966.

16. Mauro Barberis, "Le futur passé de la séparation des pouvoirs", Pouvoirs $2012, \mathrm{n}^{\circ} 143$, p. 5-15.

17. Armel Le Divellec, «L'articulation des pouvoirs dans les démocraties parlementaires européennes : fusion et migration », Pouvoirs 2012, $n^{\circ} 143$, p. 123-140.

18. Daniel Vergely, «L'équilibre des pouvoirs: une utopie constitutionnelle », RDP 2009, $n^{\circ} 5$, p. 1451-1472. 
19. Isabelle Boucobza, "Un concept erroné, celui de l'existence d'un pouvoir judiciaire », Pouvoirs 2012, $\mathrm{n}^{\circ}$ 143, p. 73-87.

20. Georges Vedel, «Le Conseil constitutionnel, gardien du droit positif ou défenseur de la transcendance des droits de l'homme », Pouvoirs 1988, n 45, p. 149-159.

21. Michel Troper, "La liberté d'interprétation du juge constitutionnel », dans Paul Amselek (dir.), Interprétation et droit, Bruxelles, Bruylant, 2010, p. 236.

22. Montesquieu, De l'esprit des lois, 1748, livre XI, chap. IV.

23. Ibid., chap. VI.

24. Abondant dans le même sens, un philosophe politique définit la démocratie comme une «forme constitutionnelle bien précise (la seule dans laquelle d'ailleurs la question de l'équilibre des pouvoirs a un sens) qui correspond à un idéal politique, un état d'esprit : celui où l'égalité permet la liberté du plus grand nombre, mais également celui qui garantit la justice pour tous » : Gil, «Équilibre des pouvoirs", Philosophie politique. Le conflit, 13 mai 2009, http:// www.leconflit.com/article-31367514.html. Voir aussi Thierry Ménissier, Éléments de philosophie politique, Paris, Ellipses, 2005.

25. Sur le complexe État de droit, liberté et démocratie, voir Drieu Godefridi, «État de droit, liberté et démocratie ", Politiques et société, vol. 23, n 1, 2004, p. 143-169.

26. Paul Duez, «Esquisse d'une définition réaliste des droits publics individuels ", Mélanges en l'honneur de Raymond Carré de Malberg, Paris, Sirey, 1933, p. 133.

27. André Doremus, «La théologie politique de Carl Schmitt », Les Études philosophiques, $\mathrm{n}^{\circ} 68$, 2004/1, p. 67.

28. Carl Schmitt, Romantisme politique, Berlin, Duncker et Humblot, 1919; Carl Schmitt, Théologie politique (1922-1969), Paris, Gallimard, 1988.

29. Mikhaïl A. Bakounine, Dieu et l'État, Genève, Imprimerie jurassienne, 1882.

30. Heinrich Meier, La leçon de Carl Schmitt, Paris, Cerf, 2014, p. 167 ; Yoan Colin et Nonfiction, «L'œuvre de Carl Schmitt, une théologie politique», Slate, 5 août 2014, http://www.slate.fr/ story/90607/impact-theologie-politique.

31. Voir dans ce sens Stéphane Bolle, «Le régime présidentiel: cache-sexe du présidentialisme? », La constitution en Afrique, 2 octobre 2017, http://www.la-constitution-enafrique.org/article-12777017.html.

32. La section 7 de l'art. $1^{\text {er }}$ de la Constitution américaine confère ce pouvoir au président : « Tout projet de loi adopté par la Chambre des représentants et par le Sénat devra, avant d'acquérir force de loi, être soumis au président des États-Unis. Si celui-ci l'approuve, il le signera ; sinon il le renverra, avec ses objections, à la Chambre dont il émane, laquelle insérera les objections in extenso dans son procès-verbal et procédera à un nouvel examen du projet. [...] Tout ordre, résolution ou vote, pour l'adoption desquels l'accord du Sénat et de la Chambre des représentants peut être nécessaire (sauf en matière d'ajournement), seront représentés au président des ÉtatsUnis, et, avant de devenir exécutoires, approuvés par lui, ou, en cas de dissentiment de sa part, adoptés de nouveau par les deux tiers du Sénat et de la Chambre des représentants, conformément aux règles et sous les réserves prescrites pour les projets de loi. »

33. «Le Gouvernement peut, pour l'exécution de son programme, demander au Parlement l'autorisation de prendre par ordonnances, pendant un délai limité, des mesures qui sont normalement du domaine de la loi », Const. 4 oct. 1958, art. 38-1 en vigueur et issu de L. const. $\mathrm{n}^{\circ}$ 2008-724, 23 juill. 2008, art. 14 de modernisation des institutions de la $V^{\mathrm{e}}$ République. On parle en l'espèce d'ordonnance ou de décret ayant force de loi ou encore d'ordonnance-loi (cas de la France et des États d'Afrique francophone, etc.) ou de décret-loi (cas des États-Unis, etc.)

34. «Le Premier ministre peut, après délibération du Conseil des ministres, engager la responsabilité du Gouvernement devant l'Assemblée nationale sur le vote d'un projet de loi de finances ou de financement de la sécurité sociale. Dans ce cas, ce projet est considéré comme adopté, sauf si une motion de censure, déposée dans les vingt-quatre heures qui suivent, est 
votée dans les conditions prévues à l'alinéa précédent. Le Premier ministre peut, en outre, recourir à cette procédure pour un autre projet ou une proposition de loi par session » : Const. 4 oct. 1958, art. 49-3 issu de L. const. $\mathrm{n}^{\circ}$ 2008-724, 23 juill. 2008, art. 24.

35. Philippe Lauvaux, Parlementarisme rationalisé et stabilité du pouvoir exécutif: quelques expériences de la réforme de l'État confrontés aux expériences étrangères, Bruxelles, Bruylant, 1988 ; Philippe Cossalter, «Vive le parlementarisme rationalisé ! ", Revue générale du droit [en ligne], $\mathrm{n}^{\circ}$ 6886, 2013; Richard Balme, «Le parlementarisme rationalisé de la cinquième République à la lumière du choix rationnel ", Revue française de science politique, $n^{\circ} 48-1,1998$, p. 147-150.

36. Les dispositions de l'art. 34-1 de la Constitution française du 4 octobre 1958 issu de l'art 12 de la Loi constitutionnelle $n^{\circ}$ 2008-724 témoignent de cette limitation optimale des possibilités de renversement du gouvernement par le Parlement: "Sont irrecevables et ne peuvent être inscrites à l'ordre du jour les propositions de résolution dont le Gouvernement estime que leur adoption ou leur rejet serait de nature à mettre en cause sa responsabilité ou qu'elles contiennent des injonctions à son égard ».

37. Voir art. 56 de la Constitution française: "Le Conseil constitutionnel comprend neuf membres, dont le mandat dure neuf ans et n'est pas renouvelable. Le Conseil constitutionnel se renouvelle par tiers tous les trois ans. Trois des membres sont nommés par le président de la République [...] En sus des neuf membres prévus ci-dessus, font de droit partie à vie du Conseil constitutionnel les anciens présidents de la République. Le président est nommé par le président de la République. Il a voix prépondérante en cas de partage. »

38. Pierre Mazeaud, "Le parlement et ses "adversaires" ", Pouvoirs 1993, n ${ }^{\circ} 64$, p. 109-122 ; Bernard Destremau, «Sur l'équilibre des pouvoirs », Commentaire, $n^{\circ} 78,1997$, p. 476-477.

39. Stéphane Rials, «Régime "congressionnel” ou régime "présidentiel” ? Les leçons de l'histoire américaine ", Pouvoirs 1984, n 29, p. 35-47.

40. Woodrow Wilson, Congressional government, Boston-New York, Houghton Mifflin, 1884.

41. Voir notamment Wanda Mastor, "L'état d'exception aux États-Unis : le USA Patriot Act et autres violations en "règle" de la Constitution", AIJC 2008-2009, n 24, p. 461 et suiv.; Christopher P. Banks, « Protecting (or Destroying) Freedom through Law: The USA Patriot Act's Constitutional Implications », dans David B. Cohen et John W. Wells (dir.), American National Security and Civil Liberties in an Era of Terrorism, New York, Palgrave MacMillan, 2004; Lindsay N. Kendrick, « Alienable Rights and Unalienable Wrongs: Fighting the "War on Terror" through the Fourth Amendment », Howard Law Journal, $n^{\circ}$ 47, 2004 ; Stephen J. Schulhofer, « No Checks, No Balances: Discarding Bedrock Constitutional Principles ", dans Richard C. Leone et Jr. Greg Anrig (dir.), The War on Our Freedoms, New York, The Century Foundation, 2003 ; Vijay Sekhon, "The Civil Rights of "Others": Antiterrorism, the Patriot Act, and Arab and South Asian American Rights in Post-9/11 American Society », Texas Journal On Civil Liberties \& Civil Rights, $\mathrm{n}^{\circ}$ 8, 2003, p. 117 ; David Cole, James X. Dempsey et Carole Goldberg, Terrorism and the Constitution: Sacrificing Civil Liberties in the Name of National Security, New York, New Press, 2002.

42. Sur la question en général, voir Joseph Owona, Droit constitutionnel et régimes politiques africains, Paris, Berger-Levrault, 1985 ; Maurice Kamto, Pouvoir et droit en Afrique noire. Essai sur les fondements du constitutionnalisme africain, Paris, LGDJ, «Bibliothèque africaine et malgache », 1987.

43. Voir Ahmed Insel, La Nouvelle Turquie d'Erdogan, du rêve démocratique à la dérive autoritaire, Paris, La Découverte, 2015 ; Nicolas Cheviron et Jean-François Pérouse, Erdogan. Nouveau père de la Turquie?, Paris, François Bourin, 2016; Jana J. Jabbour, La Turquie. L'invention d'une diplomatie émergente, Paris, CNRS, 2017. 
44. Voir Max-Valentin Robert et Ilan Berlemeont, "Analyse des résultats du référendum constitutionnel et décryptage des dynamiques électorales ", Hypothèses, 27 avril 2017, https:// ovipot.hypotheses.org/14803.

45. Voir Fatih Tombuloglu et Gulcan Kolay, "Vers une monarchie présidentielle en Turquie », Observatoire de la Turquie et de son environnement géopolitique, Institut des relations internationales et stratégiques, 13 avril 2017 ; Johanna Ollier, «Du "modèle turc" au système Erdogan: vers une nouvelle Turquie?», Revue internationale et stratégique, $n^{\circ} 106,2017$, p. 133-139.

46. Sur le concept, voir Gérard Mermet, Démocrature. Comment les médias transforment la démocratie ?, Paris, Aubier, 1987.

47. Voir Jean Gicquel, «Le présidentialisme négro-africain, le cas camerounais », Le pouvoir. Mélanges Georges Burdeau, Paris, LGDJ, 1977, p. 701 ; Marcelin Nguele Abada, État de droit et démocratisation. Contribution à l'étude de l'évolution politique et constitutionnelle au Cameroun, thèse, université de Paris 1, 1995 ; Marcelin Nguele Abada, "L'indépendance des juridictions constitutionnelles dans le constitutionnalisme des États francophones d'Afrique noire post guerre froide: l'exemple du Conseil constitutionnel camerounais ", Revue de la Fondation Raponda-Walker pour la science et la culture, $n^{\circ} 4,2010$, p. 47-90.

48. Jean Du Bois De Gaudusson, «Défense et illustration du constitutionnalisme en Afrique après quinze ans de pratique du pouvoir ", Mélanges en l'honneur de Louis Favoreu, Paris, Dalloz, 2007, p. 609 et suiv.

49. L'absence de contrôle parlementaire et juridictionnel de l'action du gouvernement et du président de la République reste la règle. Ce qui a fait dire à Jean Gicquel que les membres des autres pouvoirs sont des « agents du Président de la République » (Jean Gicquel, art. cité, p. 711, note 46 ).

50. Joseph Kankeu, «Les missions du parlement camerounais, regard sur une illusion », Juridis périodique, $\mathrm{n}^{\circ} 73,2008$, p. 42 et suiv.

51. Olivier Beaud, «La multiplication des pouvoirs», Pouvoirs 2012, $\mathrm{n}^{\circ} 143$, p. 47-49 ; David Kessler, « Les médias sont-ils un pouvoir?», Pouvoirs 2012, n 143, p. 105-112.

52. Il convient de rappeler que les 30 sénateurs (sur un total de 100) nommés par le décret présidentiel du 8 mai 2013 relevaient tous de la mouvance présidentielle, c'est-à-dire 26 directement du parti au pouvoir et 4 de ses alliés. Le Sénat camerounais tout comme l'Assemblée nationale est composé aujourd'hui d'environ 90 \% de membres du parti au pouvoir. Quel contrôle parlementaire du gouvernement ou contre-pouvoir peut-on objectivement attendre d'un tel pouvoir législatif en dehors de toute logique partisane? Voir Jean-Calvin Aba'A Oyono, «Libres propos sur le sénat en droit constitutionnel camerounais ", Revue d'étude et de recherche sur le droit et l'administration dans les pays d'Afrique, septembre 2015.

53. Const. camerounaise, art. 6, al. 2 : «Le président de la République est élu pour un mandat de sept (7) ans. Il est rééligible. » La teneur de cette disposition était l'enjeu principal du deuxième tripatouillage constitutionnel du 14 avril 2008 dont l'objectif avoué était de faire sauter le verrou de la limitation à deux mandats afin de permettre une représentation du président Paul Biya au pouvoir depuis 1982.

54. En effet, sous la pression irrésistible des bailleurs de fonds, des organisations non gouvernementales et de la clameur populaire, une vaste campagne de lutte contre la délinquance en col blanc au Cameroun a donné lieu à l'«opération Épervier ", initiative conjointement entreprise par le gouvernement central et le pouvoir judiciaire sous l'égide de nombreux organismes tels que l'Agence nationale d'investigation financière, la Commission nationale anticorruption, le Conseil de discipline budgétaire et financière, le Contrôle supérieur de l'État, la Chambre des comptes de la Cour suprême et depuis 2011, le Tribunal criminel spécial. Ces organismes dits indépendants sont censés, de façon transparente, traduire, du plus haut sommet de l'État aux tréfonds de la fonction publique et des entreprises publiques et parapubliques, les 
prédateurs des deniers publics en justice afin de réintégrer l'État dans ses droits via la répression et la restitution du corps du délit. Mais, depuis sa mise en œuvre, de nombreux observateurs soupçonnent qu'il s'agit d'un véritable processus d'élimination politique où s'entremêlent rivalités politico-tribales et où la corruption et la violation de la présomption d'innocence et bien d'autres principes élémentaires du procès équitable atteignent leur paroxysme. Ceci contre certains anciens pontes du régime regroupés dans un puissant comité dit « G11 » en vue, dit-on, d'évincer ou de persuader le président Biya ( 87 ans, dont 37 en tant que président et 58 dans la haute fonction publique) de renoncer au pouvoir. La plupart des membres soupçonnés de faire partie de ce G11 sont actuellement incarcérés dans la tristement célèbre prison centrale de Nkodengui rebaptisée depuis lors «Gouvernement de Nkodengui » qui regorge d'anciens premiers ministres, secrétaires généraux de la présidence, ministres, hauts magistrats, diplomates, officiers militaires, universitaires et bien d'autres anciens directeurs des services centraux et entreprises publiques de l'État du Cameroun. Outre une erreur de diagnostic et de thérapie, la surpolitisation de "L'opération épervier » a placé la justice camerounaise entre le marteau et l'enclume. Voir «BIYA laisse la justice trancher», Jeune Afrique économie, $n^{\circ} 388$, p. 8-113.

55. Marcelin Nguele Abada, «Ruptures et continuités constitutionnelles en République du Cameroun: réflexion à propos de la réforme constitutionnelle du 18 janvier 1996 ", Revue juridique et politique. Indépendance et coopération, vol. 50, n 3, 1996, p. 272 et suiv.

56. Agnès Ildjima Lokiam, «Séparation des pouvoirs et indépendance des cours constitutionnelles et instances équivalentes: Conseil constitutionnel de la République du Tchad ", $2^{e}$ Congrès de la Conférence mondiale sur la justice constitutionnelle, Rio de Janeiro, 16-18 janvier 2011. À noter que l'auteure est membre du Conseil constitutionnel de la République du Tchad.

57. Voir Les réformes institutionnelles au Tchad. Entre ambitions partisanes et unité nationale, rapport alternatif des organisations de la société civile tchadienne, octobre 2017.

58. Propos de l'opposant Ange Nzigou diffusés par RFI Afrique, «Gabon : le président Bongo de retour au Maroc pour sa convalescence », 16 janvier 2019.

59. Il faut préciser que la crise postélectorale a été accentuée par la crise dite anglophone née de la répression des revendications des avocats et enseignants anglophones pour le respect, à défaut de la réinstauration du fédéralisme, de l'égalité constitutionnelle entre la common law et le droit civil d'une part et d'autre part le français et l'anglais dans le Nord et Sud-ouest du pays où les élections présidentielles, législatives, municipales et sénatoriales ont été paralysées par la guerre civile qui oppose le gouvernement et les factions sécessionnistes se revendiquant d'une république autonome d'Ambazonie. Une succession de crises ayant abouti à une vague de répression sanglante avec des exécutions extrajudiciaires (plus de 3000 morts à date dans la zone anglophone selon l'ONU) et des milliers d'arrestations arbitraires à travers le pays dont les leaders séparatistes, les militants et alliés du MRC (Mouvement pour la renaissance du Cameroun) du principal opposant Maurice Kamto classé deuxième au scrutin présidentiel et considéré jusqu'ici comme "président élu et légitime » par une partie de la population et de la diaspora qui entend mener une "résistance» jusqu'au-boutiste contre ce qu'elle considère comme le «hold-up électoral ». Ces arrestations ont été suivies de cas de tortures, procès et condamnations expéditives par une justice à la fois civile et militaire considérée comme aux ordres de l'exécutif par l'opposition, la société civile et la communauté internationale qui multiplient, depuis lors, les appels au dialogue inclusif entre les protagonistes et surtout au respect de l'ordre démocratique et constitutionnel. Le constat le plus alarmant de la violation du principe de la séparation et de l'équilibre des pouvoirs et l'instrumentalisation politique subséquente de la justice par l'exécutif a été de traduire des opposants politiques, leaders, militants et alliés du MRC arrêtés à travers tout le pays dans le cadre de manifestations pacifiques pour «insurrection et hostilité contre la patrie» devant le tribunal militaire de Yaoundé en 
violation de toutes les règles de procédure et des conventions internationales signées et ratifiées par le Cameroun. Or, les tribunaux militaires camerounais sont des juridictions d'exception qui, en plus, relèvent directement du ministère de la Défense sous les ordres du président de la République, chef des forces armées. Une partie de ces prisonniers politiques a depuis été libérée sous la pression de la communauté internationale notamment l'ONU, l'UE, la France, les ÉtatsUnis, le Royaume-Uni, l'Allemagne, etc.

60. L'on parle de parlementarisme dualiste lorsque le gouvernement est à la fois politiquement responsable devant le chef de l'État (qui peut être un monarque) et le Parlement. À l'inverse, dans le parlementarisme moniste, le gouvernement est seulement responsable devant le Parlement. Parallèlement, le parlementarisme bicéphale désigne un régime de gouvernement où l'exécutif se compose à la fois d'un chef de l'état qui peut être un monarque et d'un chef du gouvernement issu de la majorité parlementaire. Dans le parlementarisme classique, la fonction $\mathrm{du}$ monarque peut être purement morale, neutre et symbolique (cas du Royaume-Uni et de l'Espagne) tout comme celle du chef de l'État peut revêtir en outre une certaine influence politique dans le parlementarisme atténué ou rationalisé (cas de l'Italie).

61. R. (on the application of Miller and another) v. Secretary of State for Exiting the European Union, 24 janv. 2017, UKSC 5, § 82 et 177 : « 82. Par la loi de 1972 [European Communities Act 1972], le Parlement a accepté et donné effet à l'adhésion future du Royaume-Uni à l'Union européenne, et [ce texte a joué le rôle d'un] point de départ stable du point de vue du droit interne. La question consiste à savoir si ce point de départ interne, adopté par le Parlement, peut-être mis de côté [...] par une décision de l'exécutif britannique sans une autorisation parlementaire expresse [en ce sens]. Nous ne pouvons pas accepter qu'un changement majeur à l'organisation constitutionnelle du Royaume-Uni soit accompli par les seuls ministres; il doit être effectué de la seule manière reconnue par la constitution du Royaume-Uni, à savoir la législation parlementaire. Cette conclusion nous semble se déduire de l'application ordinaire des concepts de base du droit constitutionnel. » « 177. J'accepte sans réserve l'importance dans notre droit constitutionnel du principe de suprématie parlementaire dans le domaine de notre droit interne établi dans les affaires Proclamations, the Tin Council et bien d'autres affaires similaires comme The Zamora ", ajoute Lord Reed, l'un des trois juges dissidents (Denis Baranger trad., http://blog.juspoliticum.com/2017/01/25/larret-miller-de-la-cour-supreme-du-royaume-uniune-traduction-des-passages-principaux/).

62. Miller (no. 2) v The Prime minister; Cherry and others v Advocate General for Scotland, 2019, UKSC 41, § 27. L'arrêt a déclaré nulle et non avenue, comme illégale et inconstitutionnelle la décision de Boris Johnson de suspendre le Parlement britannique en vue d'un Brexit sans accord. Mais, pour nombre de constitutionnalistes britanniques, la Cour suprême, au-delà des questions soumises, a réaffirmé indirectement le principe de la suprématie du Parlement sur le gouvernement puisque la manœuvre du Premier ministre visait à paralyser le Parlement dans sa compétence constitutionnelle de contrôle de l'exécutif. Voir Observatoire du Brexit, «Un jugement inédit qui marque une étape majeure dans l'évolution de la constitution britannique... », 25 sept. 2019 ; Paul Craig, « Prorogation: Constitutional Principle and Law, Fact and Causation », U.K. Const. L. Blog, 2 sept. 2019 ; Paul Craig, «Prorogation: Three Assumptions », U.K. Const. L. Blog, 10 sept. 2019.

63. "Quel que soit le mode d'organisation constitutionnelle, la séparation des pouvoirs repose sur un équilibre dynamique dans lequel le pouvoir judiciaire occupe une place particulière : il est tout à la fois l'un des pouvoirs constitués et le garant - suprême dans le cas du juge constitutionnel - du partage de leurs compétences et du respect de la loi fondamentale » (JeanMarc Sauvé, «L'étendue et les limites du pouvoir du juge », colloque européen sur le juge et la politique, 31 oct. 2014 , p. 1 ).

64. Le droit étant symbolisé par la loi sensu largissimo, l'on parlera de projet de loi lorsqu'il émane du gouvernement et de proposition de loi lorsqu'elle émane du Parlement notamment 
dans le constitutionnalisme français et, par le fait du mimétisme constitutionnel postcolonial, dans celui des États d'Afrique francophone.

65. Voir entre autres Sadock Belaid, Essai sur le pouvoir créateur et normatif du juge, Paris, LGDJ, 1974 ; Fanny Jacquelot, Le pouvoir normatif des cours constitutionnelles. Contribution à l'étude des règlements des cours constitutionnelles européennes, thèse, université Jean-Monnet, SaintÉtienne, 2003; Marie-Claire Ponthoreau, «Réflexions sur le pouvoir normatif du juge constitutionnel en Europe continentale sur la base des cas allemand et italien ", Cah. Cons. const. 2008, $\mathrm{n}^{\circ} 24$; François Saint-Bonnet, «Le pouvoir normatif des anciens juges. Le contrôle juridictionnel a priori des lois du roi », ibid. ; Jacques Arrighi de Casanova, « Pouvoir normatif du Conseil constitutionnel et stabilité de la norme », ibid. ; Denys de Béchillon, « Comment encadrer le pouvoir normatif du juge? », ibid.; Joseph Pini, « (Simples) réflexions sur le statut normatif de la jurisprudence constitutionnelle », ibid.; Delphine-Édith Emmanuel, « Le pouvoir normatif de la Cour constitutionnelle d'Afrique du Sud », Revue de droit public, n ${ }^{\circ}$ 6, nov. 2015, p. 1583 et suiv.

66. Cette thèse sous-tendue en théorie du droit par celle de l'indétermination du droit ou des normes est véhiculée notamment par la théorie réaliste de l'interprétation (TRI) née aux ÉtatsUnis et dans les pays scandinaves. L'un des grands défenseurs de ce courant de pensée, qui rencontre toutefois une vive contradiction, dans la littérature juridique civiliste francophone reste Michel Troper. Sur l'ensemble de la question, voir Ken Kress, «Legal Indeterminacy », California Law Review, $\mathrm{n}^{\circ} 77,1989$, p. 283-337 ; Lawrence B. Solum, « On the Indeterminacy Crisis: Critiquing Critical Dogma », University of Chicago Law Review, n 54, 1987, p. 462-503 ; Arnaud Le Pillouer, «Indétermination du langage et indétermination du droit », Droit et philosophie, $\mathrm{n}^{\circ}$ 9-1, 2017, p. 19 et suiv. ; Paul Amselek, « La teneur indécise du droit », Revue juridique Thémis, vol. 26, $\mathrm{n}^{\circ}$ 1, 1992, p. 2 et suiv.; Rémi Bachand, «L'indétermination et l'interprétation chez les positivistes analytiques : un échange avec Austin, Kelsen, Hart et... Dworkin », Revue de droit d'Ottawa, vol. 37, $\mathrm{n}^{\circ}$ 1, 2005, p. 35 et suiv. ; Michel Troper, « La liberté de l'interprète ", colloque, Paris, Palais du Luxembourg, 29-30 septembre 2006 ; Pierre Brunet, « Le réalisme n'est-il qu'une théorie d'interprétation ", dans Jean-Jacques Sueur (dir.), La transgression, actes du colloque de Toulon, Bruxelles, Larcier, 2013, p. 397 et suiv.; Mark Van Hoecke, «La théorie du droit (implicite) des praticiens du droit », dans Denys de Béchillon et al. (dir.), L'architecture du droit, Mélanges en l'honneur de Michel Troper, Paris, Economica, 2006, p. 977 et suiv.; Éric Millard, "Quelques remarques sur la signification politique de la théorie réaliste de l'interprétation ", ibid., p. 725 et suiv.; Francis Hamon, «Quelques réflexions sur la théorie réaliste de l'interprétation ", ibid., p. 487 et suiv. Pour un débat critique déconstructiviste et constructiviste, voir Otto Pfersmann, "Contre le néo-réalisme juridique. Pour un débat sur l'interprétation ", RFD const. 2002/2, n 50, p. 279 et suiv.; Michel Troper, «Réplique à Otto Pfersmann », ibid., p. 335 et suiv.; Otto Pfersmann, «Une théorie sans objet, une dogmatique sans théorie. En réponse à Michel Troper », RFD const. 2002/4, n 52, p. 759 et suiv. ; Étienne Picard, «Contre la théorie réaliste de l'interprétation juridique", colloque, Paris, Palais du Luxembourg, 29-30 septembre 2006.

67. Voir André Tunc, "La méthode du droit civil : Analyse des conceptions françaises ", RID comp. 1975, vol. 27, nº 4, p. 821.

68. Comme le précise Paul Amselek, à la suite de Kelsen, « dans toute norme juridique il y a une certaine indétermination: une indétermination nécessaire et irréductible, par le fait même que tout ne peut pas être prévu par le législateur, à quoi il faut ajouter, le cas échéant, d'une part, une indétermination voulue, intentionnelle, dans le but de laisser un plus ou moins grand espace de pouvoir normateur aux autorités d'application, et, d'autre part, une indétermination accidentelle induite par l'ambiguïté du langage, par les discordances apparentes entre les intentions du législateur et leur expression linguistique ou encore par les éventuelles contradictions entre les différentes normes édictées. [...] "L'interprétation par l'organe d'application du droit a toujours un caractère authentique : elle crée du droit... Il faut observer que la voie de l'interprétation 
authentique, c'est-à-dire de l'interprétation des normes par les organes juridiques qui doivent les appliquer, ne permet pas seulement de réaliser l'une d'entre les possibilités révélées par l'interprétation - à base de connaissance - des normes à appliquer, mais peut également aboutir à la création de normes qui sont tout à fait en dehors du cadre que constituent les normes à appliquer [Hans Kelsen, Théorie pure du droit, Paris, Dalloz, 1962, p. 460-461]”. [...] c'est parce que l'interprétation authentique par les organes d'application est toujours, nécessairement, création de droit que Kelsen, tout en prônant un contrôle juridictionnel de la constitutionnalité des lois pour faire prévaloir la supériorité de la Constitution sur elles, préconisait en même temps de réduire la marge de manœuvre du juge constitutionnel et de lui interdire de contrôler la constitutionnalité des lois par rapport aux Déclarations de droits ou aux Préambules, trop vagues et imprécis; il préconisait aussi, d'ailleurs, l'élection des juges constitutionnels par le Parlement en vue de donner un minimum de légitimité à leur irréductible pouvoir créateur en matière de droit constitutionnel » (Paul Amselek, «L'interprétation dans la théorie pure du droit de Hans Kelsen », dans Stéphane Beaulac et Mathieu Devinat, Interpretatio non cessat. Mélanges en l'honneur de Pierre-André Côté, Québec, Yvon Blais, 2011, p. 39 et suiv.).

69. Olivier Jouanjan, «De la vocation de notre temps pour la science du droit: modèles scientifiques et preuve de la validité des énoncés juridiques ", Revue européenne des sciences sociales [en ligne], XLI-128, 2003, p. 141.

70. Édouard Lambert, Le gouvernement des juges et la lutte contre la législation sociale aux États-Unis. L'expérience judiciaire de la constitutionnalité des lois, Paris, Marcel Giard et $C^{\text {ie }}$, 1921 ; Édouard Lambert, Le gouvernement des juges, Paris, Dalloz, 2005 ; Michel Troper, Le gouvernement des juges, mode d'emploi, Québec, Presses de l'université Laval, 2005 ; Sévérine Brondel, Norbert Foulquier et Luc Heuschling (dir.), Gouvernement des juges et démocratie, Paris, Éditions de la Sorbonne, 2001 ; Patrick Wafeu Toko, « Le juge qui crée le droit est-il un juge qui gouverne? », Les Cahiers de droit, vol. 54, n 1, 2013, p. 145 et suiv.

71. Voir Newton Tavares Filho, Juger les lois: l'activisme juridictionnel du tribunal fédéral suprême du Brésil dans le cadre de la constitution de 1988, thèse, université de Paris 1, 2016.

72. C'est dans le but d'anéantir le "gouvernement des juges" ou de réduire à sa plus simple expression l'«activisme judiciaire » que l'art. 5 du Code civil français, issu de la loi 1803/03/05 promulguée le 15 mars 1803, dispose qu'«il est défendu aux juges de prononcer par voie de disposition générale et réglementaire sur les causes qui leur sont soumises ».

73. Cet état de choses est de nature à susciter une véritable crise du paradigme de l'État de droit et de son support, la démocratie libérale du point de vue de la légitimité et de la représentativité du peuple. Car, comment concevoir qu'un juge nommé par un individu, puisse, parfois pour des motifs purement idéologiques (conservatisme, progressisme, libertarisme, socialisme, économisme, écologisme, etc.), s'opposer efficacement, fût-ce au nom du droit, de par sa décision revêtue de la force exécutoire, à une autre décision prise par un élu mandaté au suffrage universel par des millions de citoyens? Curieuse réalité de l'État de droit et de la démocratie libérale! Pour d'autres critiques du paradigme "malade» de la démocratie (néo)libérale, notamment à l'encontre du législatif et de l'exécutif, voir Réfractions, recherches et expressions anarchistes, $n^{\circ} 12,2004$, https://refractions.plusloin.org/spip.php?rubrique38.

74. S'il en va en ainsi, est-il besoin de rappeler que le droit positif n'a souvent de sens que par son interprétation et concrétisation par le juge sans quoi il peut demeurer un corpus de règles inertes, voire un simple texte en quête de sens?

75. Hormis le champ du droit pénal avec le droit de grâce et de remise des peines ou encore le droit d'amnistie permettant concurremment au président de la République et au Parlement d'annihiler des décisions du pouvoir judiciaire, les pouvoirs exécutif et législatif n'ont a priori aucune emprise sur ce premier d'autant plus que l'exercice de ces prérogatives, quoique au nom du droit, du fait de l'atteinte portée de façon incidente à l'indépendance de la justice et des 
possibles répercussions sociales inestimables, est souvent très mal apprécié par l'opinion publique dans le contexte d'une démocratie libérale.

76. Charles Eisenmann, "L'esprit des lois et la séparation des pouvoirs », Mélanges en l'honneur de Raymond Carré de Malberg, Paris, Sirey, 1933, p. 164 et suiv.

77. Yves Meny, «Le cumul des mandats ou l'impossible séparation des pouvoirs?", Pouvoirs 1993, n 64, p. 129 et suiv.

78. Mathieu Touzeil-Divina, «Printemps et révolutions arabes : un renouveau pour la séparation des pouvoirs? ", Pouvoirs 2012, n 143, p. 29 et suiv.

79. Il s'agit notamment d'une collaboration ou séparation souple des pouvoirs. Voir, dans ce sens, Julien Boudon, « La séparation des pouvoirs aux États-Unis », ibid., p. 113 et suiv.

80. Agnès Roblot-Troizier, «Un concept moderne : séparation des pouvoirs et contrôle de la loi », ibid., p. 89 et suiv.

81. La juridiction constitutionnelle est, de ce point de vue idéaliste, considérée seulement comme un pouvoir neutre et gardien de la constitution (voir Sandrine Baume, « De l'usage des pouvoirs neutres ", ibid., p. 22 et suiv.).

82. Voir dans ce sens, Michel Miaille, «Désordre, droit et science », dans Paul Amselek (dir.), Théorie du droit et science, Paris, PUF, 1993, p. 87 et suiv.

83. Un État-multination est un État formé sur une base idéologique, identitaire, civique, voire ethnique, de deux ou plusieurs nations existantes en tant que communautés ou entités sociales différentes, chacune ayant conscience de sa spécificité ou souveraineté et manifestant le désir de les conserver. Il en va et en fut ainsi du Royaume-Uni, de l'Union européenne (dans une moindre mesure), de l'URSS, de l'Autriche-Hongrie, de la Tchécoslovaquie, etc. Voir notamment Seydou Madani Sy, «Formes et structures de l'État: l'État multinational et le pluralisme politique », Présence africaine, $\mathrm{n}^{\circ} 127-128,1983$, p. 298 et suiv.; Stéphane Pierré-Caps, La multination: l'avenir des minorités en Europe centrale et orientale, Paris, Odile Jacob, 1995 ; Olivier Audéoud, Jean-Denis Mouton et Stéphane Pierré-Caps, L'État multinational et l'Europe, Nancy, PUN, 2000 ; Muriel Rambour, «Les mutations de l'État-nation en Europe. Réflexions sur les concepts de multination et de patriotisme constitutionnel », Pôle Sud, n 14, 2001, p. 17 et suiv.; Christophe Parent, Le concept d'État fédéral multinational : essai sur l'union des peuples, Bruxelles, Peter Lang, 2011 ; Michel Seymour et Guy Laforest, Le fédéralisme multinational, un modèle viable?, Bruxelles, Peter Lang, 2011.

84. . Le libéralisme est une doctrine politique qui prône la garantie des droits et libertés naturels de l'individu au sein de l'État qui ne devrait tout au plus, au nom de l'intérêt général, qu'en assurer l'encadrement par le droit positif et non fixer la limitation.

\section{RÉSUMÉS}

L'équilibre des pouvoirs n'est qu'un idéaltype. Il recèle dès lors une dimension hypothétique et utopique en ce qu'il ne peut jamais se réaliser pleinement même dans le contexte des démocraties dites évoluées. Cet idéal inaccessible d'équilibre contraste avec la réalité empirique d'un déséquilibre contextuel des pouvoirs en faveur soit de l'exécutif selon que l'on se trouve dans un régime de type présidentiel, soit du législatif, dans un régime de type parlementaire et soit plus généralement $d u$ judiciaire dans toute démocratie libérale ou État de droit où l'on observe une régulation, voire un contrôle, soit-il symbolique, en dernier ressort des autres pouvoirs par le pouvoir judiciaire incarné par la juridiction constitutionnelle. 
The balance of powers is only an ideal type. Therefore, it contains a hypothetical and utopian dimension so that it can never be fully realized even in the context of the advanced democracies. This inaccessible ideal of balance contrasts with the empirical reality of a contextual imbalance of powers in favor of the executive in a presidential regime, the legislative in a parliamentarian regime and generally, the judicial power in any liberal democracy or the rule of law where there is ultimately a regulation or a symbolic control of the other powers by the judicial one embodied by the constitutional court.

\section{INDEX}

Mots-clés : équilibre, déséquilibre, pouvoir, constitution

Keywords : balance, imbalance, power, constitution

\section{AUTEUR}

\section{ÉRIC FOKOU}

Doctorant en droit, Université Laval-Canada et Université de Nantes-France. 